\title{
Is Exchange Rate Stabilization an Appropriate Cure for the Dutch Disease?*
}

\author{
Ruy Lama and Juan Pablo Medina \\ International Monetary Fund
}

This paper evaluates how successful a policy of exchange rate stabilization is in counteracting the negative effects of a Dutch disease episode. We consider a small open-economy model that incorporates nominal rigidities and a learning-bydoing externality in the tradable sector. The paper shows that leaning against an appreciated exchange rate can prevent an inefficient loss of tradable output but at the cost of generating a misallocation of resources in other sectors of the economy. The paper also finds that welfare is a decreasing function of exchange rate intervention. These results suggest that stabilizing the nominal exchange rate in response to a Dutch disease episode could be highly distortionary.

JEL Codes: E52, F31, F41.

\section{Introduction}

Small open economies experience recurrent episodes of exchange rate appreciation in response to different types of shocks. ${ }^{1}$ When an appreciation induces a contraction of the exporting manufacturing sector, then an economy usually is diagnosed as having a Dutch

${ }^{*}$ Copyright (C) 2012 International Monetary Fund. We thank Mick Devereux, Carl Walsh, Jon Faust, Alok Johri, Michel Juillard, Leonardo Martínez, Diego Restuccia, Jorge Roldós, Carlos Urrutia, Rodrigo Valdés, Adrián Armas, Nicolás Magud, Marco Vega, and seminar participants at the 2009 Society of Computational Economics Conference, the 2010 LACEA Meeting, and the Third Annual IJCB Fall Conference at the Bank of Canada. All remaining errors are ours. The views expressed herein are those of the author and should not be attributed to the IMF, its Executive Board, or its management. Author e-mails: rlama@imf.org; jmedina@imf.org.

${ }^{1}$ For instance, if an economy discovers valuable natural resources (e.g., oil), its terms of trade improve, or it faces a supply shock such as higher productivity relative to the main trade partners, then its real exchange rate will appreciate. 
disease. $^{2}$ The Dutch disease phenomenon is a source of concern for policymakers to the extent that a smaller tradable sector might undermine future possibilities of growth and employment creation. In this context, policymakers face a key question: What type of policy intervention can counteract the negative effects of a Dutch disease episode? In this paper we evaluate the merits of one of the policy options commonly implemented by governments: exchange rate stabilization through monetary policy.

One way to prevent tradable output from falling below the efficient level is to depreciate the real exchange rate through monetary policy. A policy of exchange rate depreciation can be successful in preventing a contraction of tradable output, but it will have allocative effects in the economy. In this paper we evaluate in a dynamic stochastic general equilibrium (DSGE) model what the cost and benefits of this policy intervention are in terms of macroeconomic stability and welfare.

To illustrate the effects of a Dutch disease episode, figure 1 shows the behavior of several Canadian macroeconomic variables in recent years. In the period 2002-07, the terms of trade improved 25 percent. This increase in the terms of trade was driven by a worldwide boom in commodity prices - in particular, a surge in oil and gas prices. Consistent with the empirical evidence of commodity currencies, panel A shows that the real effective exchange rate also appreciated around 25 percent. $^{3}$ These changes in relative prices had an impact in the reallocation of resources across sectors in the economy. For instance, panel B shows that the ratio of consumption to GDP increased about 8 percentage points in the same period, reflecting the wealth effects from higher commodity prices.

On the other hand, panel $\mathrm{C}$ shows the share of manufacturing production over GDP for Canada. The period of exchange rate appreciation coincides with a contraction of 4 percentage points of

\footnotetext{
${ }^{2}$ The term "Dutch disease" was introduced to describe the situation experienced in the Netherlands in the 1960s after the discovery of gas deposits in the North Sea. The discovery of natural resources was followed by an appreciation of the real exchange rate and a crowding out of the manufacturing exports. More recently, the term is also used to describe the negative effects on exports induced by foreign aid, remittances, capital inflows, or an improvement in the terms of trade.

${ }^{3}$ For a reference on commodity currencies, see Chen and Rogoff (2003).
} 


\section{Figure 1. Effects of Higher Terms of Trade in Canada}
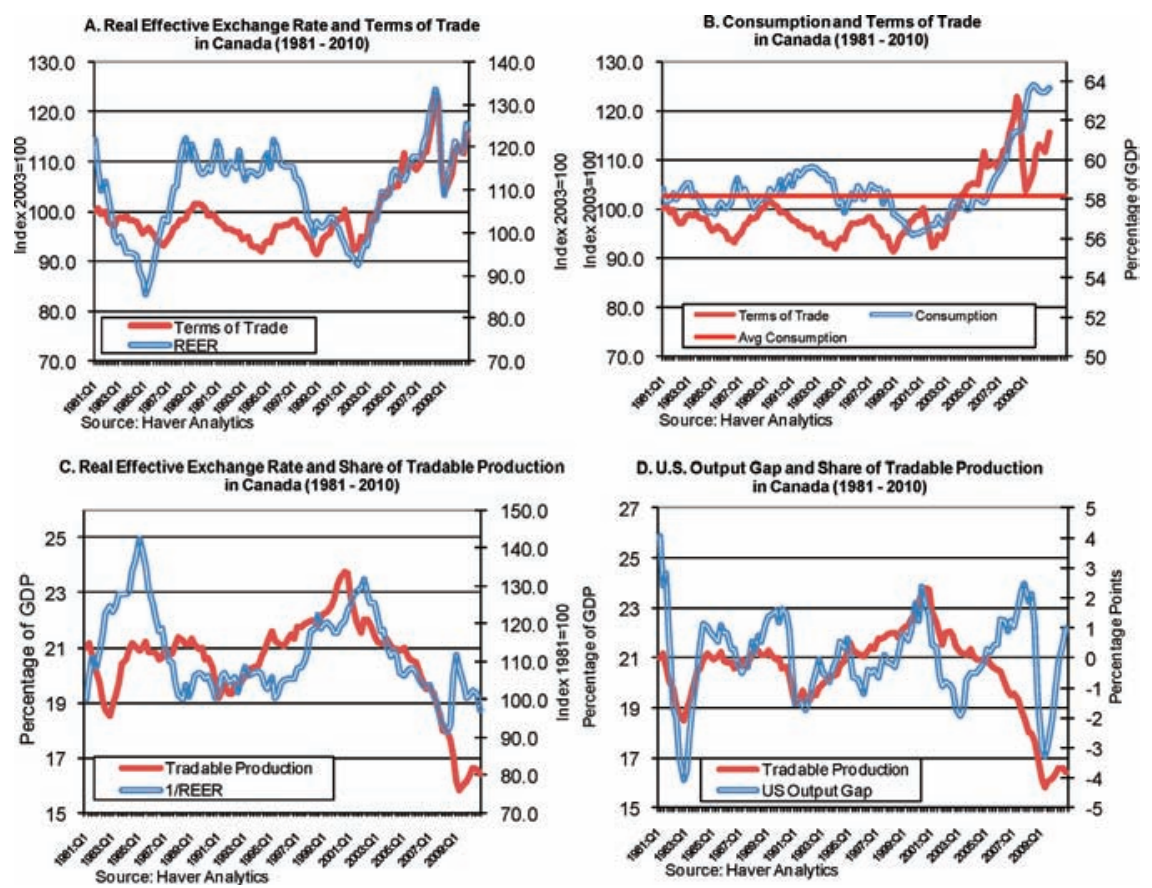

GDP in the share of manufacturing production. Notice that this reallocation process is unprecedented in the Canadian economy in terms of the size and the timing of the contraction. Panel D shows that in the last twenty years, Canadian manufacturing production experienced a maximum contraction of 2 percentage points of GDP every time it entered into a recession, which coincides with a recession in the United States. The most recent episode of exchange rate appreciation shows a larger decline in manufacturing production unrelated to the U.S. business cycle, pointing out some Dutch disease effects in the economy. We consider Canada an interesting case study to the extent that it is an economy with a sizable manufacturing export sector and, at the same time, with business cycles sensitive to variations in commodity prices. These two features make the potential costs of a Dutch disease episode larger compared with other small open economies.

In a standard frictionless two-sector real business-cycle model, the reallocation between the tradable and non-tradable sector, such 
as the one observed in Canada, is the efficient response to an increase in the terms of trade. Higher terms of trade will increase the demand for tradable and non-tradable goods, and as a consequence wages will be higher in the economy. Taking international prices as given, higher wages will reduce the production of tradable goods, and the demand will be satisfied with imports from the rest of the world. In this situation there is no rationale for government intervention, and protecting the tradable sector will reduce overall welfare.

If we consider an economy with nominal rigidities in domestic prices, then variations in the terms of trade can reduce welfare if these variations generate domestic inflation volatility. In this situation, the role of monetary policy is to stabilize the set of prices with nominal rigidities and allow the nominal exchange rate to adjust freely. Considering Canada as an example, the policy prescription to higher terms of trade in a model with nominal rigidities will be to stabilize domestic inflation and allow a nominal exchange rate appreciation in order to absorb the external shock. This policy leads to a real exchange rate appreciation and hence to a reallocation of resources from the tradable to the non-tradable sector, similar to what has been observed in the Canadian case.

However, if there are additional frictions besides nominal rigidities, the full flexibility of the exchange rate might not necessarily be a desirable property of the optimal monetary policy, and some degree of exchange stabilization might be required. In this work we focus on one friction commonly discussed in the Dutch disease literature: the learning-by-doing (LBD) externality in the tradable sector. Considering an LBD mechanism, a reduction in tradable output will lead to lower productivity in that sector and a decrease of future production. If this mechanism is not internalized by the firms, then there will be an inefficient loss of tradable production and hence a role for policy intervention.

One policy option commonly used to influence tradable production is stabilizing the exchange rate. ${ }^{4}$ Intervening in the foreign exchange rate market can prevent a fall of tradable production below

\footnotetext{
${ }^{4}$ For empirical evidence on exchange rate stabilization across countries, see Calvo and Reinhart (2002).
} 
the efficient level. However, if we consider nominal rigidities in alternative sectors of the economy, as the empirical evidence suggests, then an intervention in the foreign exchange rate market could also induce a misallocation of resources. ${ }^{5,6}$ Policymakers face a trade-off between correcting the LBD externality in the tradable sector and ensuring an efficient allocation of resources across productive sectors. In the paper we evaluate this trade-off and analyze how successful a policy of exchange rate stabilization is in addressing the potential inefficiencies during a Dutch disease episode. ${ }^{7}$

The main result of the paper is that exchange rate intervention is a welfare-reducing policy to counteract the effects of the Dutch disease. On the one hand, a policy of exchange rate stabilization can prevent a contraction of tradable production below the efficient level. On the other hand, stabilizing the exchange rate exacerbates the effects on aggregate demand generated by an improvement of the terms of trade and hence increases macroeconomic volatility. In a version of the model calibrated to the Canadian economy, we find that the costs in terms of macroeconomic volatility and misallocation of resources far exceed any benefits obtained from a more stable exchange rate. The intuition for this result is that exchange rate intervention through monetary policy is a blunt instrument to correct the LBD externality. Stabilizing the exchange rate not only expands tradable output but also stimulates all sectors in the economy in tandem, which turns out to be highly distortionary in a context of higher terms of trade. These conclusions are robust to several modifications of the baseline model such as larger LBD

\footnotetext{
${ }^{5}$ For a reference of sticky prices in alternative sectors of the economy, see Bils and Klenow (2004).

${ }^{6}$ If we assume that prices in some sectors of the economy are sticky and the nominal exchange rate is stabilized, then the real exchange rate adjustment is going to come partially from an increase in domestic inflation. If we assume either a pricing behavior as in Rotemberg (1982) or Calvo (1983), the higher inflation induced in the sticky sectors due to the exchange rate stabilization will generate a loss of resources in those sectors and hence a misallocation of resources.

${ }^{7}$ In this paper we consider the case of exchange rate stabilization through the short-term interest rate. Under the assumption of perfect asset substitutability of domestic and foreign bonds, the stabilization through the short-term interest rate and foreign exchange rate intervention are equivalent.
} 
externalities, LBD in the non-tradable sector, incomplete exchange rate pass-through for imported goods, and alternative preferences that eliminate the wealth effects on labor supply.

This paper is related to an extensive Dutch disease literature. Van Wijnbergen (1984), Krugman (1987), and Caballero and Lorenzoni (2009) evaluate alternative policy interventions in the context of Dutch disease episodes. These authors differ regarding which friction generates a misallocation of resources in response to an appreciated exchange rate. The first two authors consider an LBD externality in the tradable sector, while Caballero and Lorenzoni analyze the case of financial frictions in the exportable sector. Our paper also conducts a policy evaluation in response to a Dutch disease, considering as the starting point a New Keynesian small open-economy model. The framework is similar to the work of Adolfson et al. (2007), Lubik and Schorfheide (2007), and Justiniano and Preston (2008), who estimate and evaluate different versions of the New Keynesian model for small open economies. We depart from these models by introducing an LBD mechanism in the manufacturing exportable sector. Chang, Gomes, and Schorfheide (2002) and Cooper and Johri (2002) provide empirical evidence regarding the quantitative importance of the LBD mechanism. This paper contributes to the Dutch disease literature by performing a quantitative evaluation on the merits of exchange rate stabilization to correct the LBD externality.

A caveat is in order. Our model assumes transitory variations of the terms of trade and temporary effects of the learning-by-doing externality on tradable output. Hence, we resort to a first-order approximation around a well-defined steady state to solve for the model. In practice, however, some countries might experience highly persistent shocks that can have permanent effects on the size of the manufacturing sector. For those episodes, the use of global methods could be a better approach to evaluate policy options for long-lasting effects of the Dutch disease.

The rest of the paper is organized as follows. Section 2 describes the small open-economy model. Section 3 discusses the calibration strategy for the model. Section 4 presents the main findings of the paper. Section 5 shows the welfare analysis. Section 6 characterizes the optimal fiscal and monetary rules in response to a Dutch disease episode. Section 7 presents some model extensions. Section 8 concludes. 


\section{A Small Open Economy with Learning-by-Doing}

In this section we present a multi-sector small open-economy model with nominal rigidities and an LBD externality in the tradable sector. The model is built along the lines of Christiano, Eichenbaum, and Evans (2005), Adolfson et al. (2007), and Smets and Wouters (2007). We depart from these models by introducing LBD externality in the tradable sector following Chang, Gomes, and Schorfheide (2002) and Cooper and Johri (2002). The model captures two features of economies that can be exposed to a Dutch disease: a large commodity sector and an LBD externality in the manufacturing sector. This last feature generates a misallocation of resources during a boom of commodity prices and calls for government intervention.

The model considers three sectors. The first sector produces a manufactured home good $(H) .{ }^{8}$ The second produces a non-tradable good $(N)$. The third produces a commodity good, which is exported entirely at a given international price. Consumer preferences are defined over final consumption good and leisure. The model considers sticky prices in the tradable and non-tradable sector which generate real effects for changes in monetary policy. The key innovation with respect to standard New Keynesian models is the introduction of an LBD externality in the manufacturing tradable sector. Appendix 1 describes all the equilibrium conditions of the model.

\subsection{Households}

The household's preferences are defined over consumption and labor:

$$
U_{t}=E_{t}\left[\sum_{i=0}^{\infty} \beta^{i} u\left(C_{t+i}-h \mathcal{H}_{t+i}, L_{t+i}\right)\right],
$$

where $L_{t}$ is labor effort, $C_{t}$ is its total consumption, and the external habit component is defined by $\mathcal{H}_{t+i}=C_{t+i-1}$. Households have access to three types of assets: money $\mathcal{M}_{t}$, one-period non-contingent foreign bonds $B_{t}^{*}$, and one-period domestic contingent bonds $\mathcal{D}_{t+1}$

\footnotetext{
${ }^{8}$ For the rest of the paper, we are going to use the terms tradable production and home goods production indistinctively, referring to the good that is produced domestically and can be exported.
} 
which pay out one unit of domestic currency in a particular state. ${ }^{9}$ The household budget constraint is given by

$$
\begin{aligned}
& P_{t}^{C} C_{t}+E_{t}\left\{d_{t, t+1} \mathcal{D}_{t+1}\right\}+\mathcal{E}_{t} B_{t}^{*}+\mathcal{M}_{t}= \\
& W_{t} L_{t}+\Pi_{t}+\mathcal{D}_{t}+\mathcal{E}_{t} B_{t-1}^{*}\left(1+i_{t-1}^{*}\right) \Theta\left(\left(\mathcal{B}_{t-1}\right)\right)+\mathcal{M}_{t-1}
\end{aligned}
$$

where $P_{t}^{C}$ is the price of consumption, $\Pi_{t}$ is profits received from all domestic firms, $W_{t}$ is the nominal wage, and $\mathcal{E}_{t}$ is the nominal exchange rate. $d_{t, t+1}$ is the period $t$ price of one-period domestic contingent bonds divided by the probability of the occurrence of the state. The financial costs of the foreign bond $B_{t}^{*}$ are defined by the foreign interest rate $i_{t}^{*}$ and the risk premium $\Theta(.){ }^{10}$

\subsection{Firms}

There are four types of firms in the economy: final goods producers, retailers, intermediate goods producers, and capital producers. Next, we describe the structure of all these firms.

\subsubsection{Final Goods Producers}

The final goods producers $Y_{t}^{F}$ combine home-produced inputs $Y_{t}^{D H}$, imports $Y_{t}^{M}$, and non-tradable inputs $Y_{t}^{D N}$ according to a constant elasticity of substitution (CES) production function:

$$
\begin{aligned}
& Y_{t}^{F}=\left[\alpha_{Y}^{1 / \eta_{Y}}\left(Y_{t}^{T}\right)^{\frac{\eta_{Y}-1}{\eta_{Y}}}+\left(1-\alpha_{Y}\right)^{1 / \eta_{Y}}\left(Y_{t}^{D N}\right)^{\frac{\eta_{Y}-1}{\eta_{Y}}}\right]^{\frac{\eta_{Y}}{\eta_{Y}-1}}, \\
& Y_{t}^{T}=\left[\gamma_{Y}^{1 / \omega_{Y}}\left(Y_{t}^{D H}\right)^{\frac{\omega_{Y}-1}{\omega_{Y}}}+\left(1-\gamma_{Y}\right)^{1 / \omega_{Y}}\left(Y_{t}^{M}\right)^{\frac{\omega_{Y}-1}{\omega_{Y}}}\right]^{\frac{\omega_{Y}}{\omega_{Y}-1}},
\end{aligned}
$$

\footnotetext{
${ }^{9}$ In the model, money plays the role of a unit of account. Considering an alternative specification, such as separable money in the utility function, does not modify the quantitative results of the model.

${ }^{10}$ This premium is a function of the net foreign asset positions relative to GDP, $\mathcal{B}_{t}=\frac{\mathcal{E}_{t} B_{t}^{*}}{P_{Y, t} Y_{t}}$, where $P_{Y, t} Y_{t}$ is nominal GDP and $B_{t}^{*}$ is the aggregate net asset position of the economy. This premium is introduced as a technical device to ensure stationarity (see Schmitt-Grohé and Uribe 2003).
} 
where $Y_{t}^{T}$ denotes the production of tradable inputs. $\alpha_{Y}$ and $\eta_{Y}$ are the share of tradable inputs and the elasticity of substitution for the final goods production function, respectively. $\gamma_{Y}$ and $\omega_{Y}$ are the share of domestic inputs and the elasticity of substitution for the tradable goods production function.

\subsubsection{Retailers}

We assume that firms in the retail sector sell home goods $Y_{t}^{H}$ and non-tradable goods $Y_{t}^{N}$ in two separate stages. First, there is an assembler that combines the differentiated intermediate good indexed by $j \in[0,1]$ in each sector $J=H, N$ to produce $Y_{t}^{J}$. The technology is a constant elasticity of substitution aggregator given by

$$
Y_{t}^{J}=\left(\int_{0}^{1} Y_{t}^{J}(j)^{\frac{\epsilon_{J}-1}{\epsilon_{J}}} d j\right)^{\frac{\epsilon_{J}}{\epsilon_{J}-1}},
$$

where $\epsilon_{J}$ is the elasticity of substitution between a variety of goods. The optimal choice for each assembler yields a demand function for intermediate goods:

$$
\begin{aligned}
Y_{t}^{J}(j) & =\left(\frac{P_{t}^{J}(j)}{P_{t}^{J}}\right)^{-\epsilon_{J}} Y_{t}^{J}, \\
P_{t}^{J} & =\left(\int_{0}^{1} P_{t}^{J}(j)^{1-\epsilon_{J}} d j\right)^{\frac{1}{1-\epsilon_{J}}} .
\end{aligned}
$$

Second, retailers of each intermediate good have monopolistic power and set their prices according to the Calvo (1983) framework. Every period, a fraction $\left(1-\theta_{J}\right)$ of retailers in sector $J=H, N$ set their prices optimally. The optimal price $P_{t}^{J *}(j)$ chosen by each retailer maximizes the expected present value of profits:

$$
E_{t}\left[\sum_{i=0}^{\infty}\left(\theta_{J}\right)^{i} \Lambda_{t, t+i}\left(\frac{P_{t}^{J *}(j)-P_{t+i}^{W J}}{P_{t+i}^{J}}\right) Y_{t+i}^{J}(j)\right],
$$

where $\Lambda_{t, t+i}$ is the stochastic discount factor, and $P_{t}^{W J}$ is the wholesale price of the intermediate good of sector $J=H, N . P_{t}^{W J}$ is determined competitively in the intermediate goods market. The problem of the intermediate goods producers is explained in the next section. 


\subsubsection{Intermediate Goods Producers}

There is a continuum of firms in the non-tradable sector. Each firm $n \in[0,1]$ produces output $Y_{t}^{N}(n)$ using physical capital and labor, $K_{t}^{N}(n)$ and $L_{t}(n)$, respectively. The production function is given by

$$
Y_{t}^{N}(n)=A_{t}^{N}\left[K_{t}^{N}(n)\right]^{\eta_{N}}\left[L_{t}^{N}(n)\right]^{1-\eta_{N}},
$$

where $A_{N, t}$ denotes an aggregate productivity shock in the sector.

The tradable sector is subject to an LBD externality. The production function of each representative firm $h \in[0,1]$ in this sector is given by

$$
Y_{t}^{H}(h)=A_{t}^{H}\left[H_{t}(h)\right]^{\lambda_{H}}\left[K_{t}^{H}(h)\right]^{\eta_{H}}\left[L_{t}^{H}(h)\right]^{\gamma_{H}},
$$

where $A_{t}^{H}, K_{t}^{H}(h)$, and $L_{t}^{H}(h)$ denote an aggregate productivity shock, capital, and labor, respectively. $H_{t}(h)$ is the level of organizational capital in the home goods sector. We restrict the technology to the case of constant returns to scale, that is, $\lambda_{H}+\eta_{H}+\gamma_{H}=1$. The organizational capital evolves according to the following law of motion:

$$
H_{t+1}(h)=\left[H_{t}(h)\right]^{\phi_{H}}\left[\bar{Y}_{t}^{H}\right]^{\mu_{H}},
$$

where $\bar{Y}_{t}^{H}$ is the production at the industry level, $\left(1-\phi_{H}\right)$ is the depreciation rate of organizational capital, and $\mu_{H}$ is the elasticity of organizational capital with respect to current output. We restrict the exponents of the law of motion to the case of constant returns to scale, that is, $\phi_{H}+\mu_{H}=1$. This is the same specification as in Cooper and Johri (2002). These authors found empirical evidence for this specification of LBD using plant-level and national income and product accounts data. In a more recent paper, Clarke (2008) found evidence of LBD in the Canadian manufacturing sector.

In this paper, we follow the same interpretation of organizational capital as in Lev and Radhakrishnan (2003): "Organizational capital is thus an agglomeration of technologies-business practices, processes and designs, including incentive and compensation systems - that enable some firms to consistently extract out of a given level of resources a higher level of product and a lower cost than 
other firms." Hence in the model, higher production in the tradable sector leads to an increase in organizational capital, which improves the efficiency in the sector and generates additional production with the same level of labor and physical capital.

\subsubsection{Capital Producers}

Capital producers $J=H, N$ own and rent sector-specific capital to firms in the home and non-tradable goods sectors, respectively. The aggregate investment of each type of capital is a composite of home, foreign, and non-tradable goods as in the case of the final good. The representative firm of each type of capital $J$ solves the following problem:

$$
V_{t}^{J}=\max _{K_{t+i}^{J}, I_{t+i}^{J}} E_{t}\left\{\sum_{i=0}^{\infty} \Lambda_{t, t+i} \frac{Z_{t+i}^{J} K_{t+i}^{J}-P_{t+i}^{C} I_{t+i}^{J}}{P_{t+i}^{C}}\right\},
$$

subject to the law of motion of physical capital:

$$
K_{t+1}^{J}=(1-\delta) K_{t}^{J}+S\left(\frac{I_{t}^{J}}{I_{t-1}^{J}}\right) I_{t}^{J},
$$

where $Z_{t}^{J}$ is the rental rate of physical capital, $V_{t}^{J}$ is the present discounted value of profits, and $\delta$ is the depreciation rate of capital in sector $J . S($.$) characterizes the adjustment cost for investment. { }^{11}$

\subsection{Commodity Sector}

We assume that the exports of commodities $X_{t}$ in this economy evolve exogenously according to the following process:

$$
X_{t}=\left[X_{t-1}\right]^{\rho_{x}}\left[X_{0}\right]^{1-\rho_{x}} \exp \left(\varepsilon_{t}^{x}\right),
$$

\footnotetext{
${ }^{11}$ We follow Christiano, Eichenbaum, and Evans (2005) and specify an investment adjustment cost that satisfies the following conditions: $S(1)=1, S^{\prime}(1)=0$, $S^{\prime \prime}(1)=-\mu_{S}<0$. This assumption generates inertia in investment that is consistent with a time-to-build specification.
} 
where $\varepsilon_{t}^{x} \sim N\left(0, \sigma_{x}^{2}\right)$ is a stochastic shock and $\rho_{x}$ measures the persistency of the process. ${ }^{12}$ We assume that the commodity price $P_{t}^{x}$ follows the stochastic process

$$
P_{t}^{x}=\left[P_{t-1}^{x}\right]^{\rho_{p x}}\left[P_{0}^{x}\right]^{1-\rho_{p x}} \exp \left(\varepsilon_{t}^{p x}\right),
$$

where $\varepsilon_{t}^{p x} \sim N\left(0, \sigma_{p x}^{2}\right)$ is a stochastic shock and $\rho_{p x}$ measures the persistency of the commodity prices.

\subsection{Monetary Policy Rule}

The monetary policy is characterized by a Taylor-type rule:

$$
\left(\frac{1+i_{t}}{1+i}\right)=\left(\frac{1+i_{t-1}}{1+i}\right)^{\psi_{i}}\left(\frac{Y_{t}}{\bar{Y}_{t}}\right)^{\left(1-\psi_{i}\right) \psi_{y}}\left(\frac{\pi_{C, t}}{\bar{\pi}}\right)^{\left(1-\psi_{i}\right) \psi_{\pi}}\left(\frac{s_{t}}{\bar{s}}\right)^{\left(1-\psi_{i}\right) \psi_{s}}
$$

where $i_{t}, Y_{t}, \pi_{C, t}$, and $s_{t}$ are the nominal interest rate, GDP, CPI inflation, and the nominal exchange rate depreciation, respectively. The parameters $\psi_{y}, \psi_{\pi}$, and $\psi_{s}$ are the weights assigned in the Taylor rule to stabilize deviations of output, inflation, and depreciation rate, with respect to their steady-state values. The parameter $\psi_{i}$ indicates the degree of interest rate smoothing in the Taylor-type rule. In the rule, the key parameter that is going to be evaluated is the intensity of exchange rate stabilization $\psi_{s}$.

\subsection{Market Clearing Conditions}

In every period, markets clear for labor, capital, intermediate home and non-tradable goods, the final good, and international bonds. The market clearing conditions for labor and capital are given by

$$
\begin{gathered}
L_{t}=\left(\int_{0}^{1} L_{t}^{N}(n) d n\right)+\left(\int_{0}^{1} L_{t}^{H}(h) d h\right), \\
K_{t}^{J}=\left(\int_{0}^{1} K_{t}^{J}(j) d j\right), J=H, N .
\end{gathered}
$$

\footnotetext{
${ }^{12} \mathrm{We}$ assume an exogenous process for commodity exports to simplify the model. In section 7 we consider a more realistic setup in which the commodity sector hires physical capital and labor. In that case, the main qualitative results of the model are not modified.
} 
The market clearing conditions for home and non-tradable intermediate goods are

$$
\begin{gathered}
Y_{t}^{D N}=Y_{t}^{N}, \\
Y_{t}^{D H}+C_{t}^{H *}=Y_{t}^{H},
\end{gathered}
$$

where $C_{t}^{H *}=\gamma^{*}\left(\frac{P_{H, t}}{\mathcal{E}_{t} P_{F, t}^{*}}\right)^{-\eta^{*}} C_{t}^{*}$ is the foreign demand for home goods, and $C_{t}^{*}$ is the aggregate foreign consumption. Finally, the equilibrium conditions in the final goods production and international bonds are given by

$$
\begin{gathered}
Y_{t}^{F}=C_{t}+I_{t}^{H}+I_{t}^{N} \\
\mathcal{E}_{t} B_{t}^{*}=\left(1+i_{t-1}^{*}\right) \Theta\left(\mathcal{B}_{t-1}\right) \mathcal{E}_{t} B_{t-1}^{*}+P_{t}^{M} Y_{t}^{M}-P_{t}^{H} C_{t}^{H *}-P_{t}^{x} X_{t} .
\end{gathered}
$$

\section{Calibration and Solution Method}

To evaluate the quantitative predictions of the model, we loglinearize the equations around the steady state. To ensure stationarity of the model, we introduce a risk premium term that depends on the net foreign asset position (see Schmitt-Grohé and Uribe 2003). We use the algorithm proposed by Schmitt-Grohé and Uribe (2004b) to solve the rational expectations model, which provides an efficient implementation of the solution method proposed by Blanchard and Kahn (1980). ${ }^{13}$

The model is calibrated to match some features of the Canadian data, as an example of a small open economy exposed to terms-oftrade shocks. Table 1 describes the parameter values used in the calibration of the model. Most of the parameters for the real block of the model are obtained from the Bank of Canada Quarterly Projection Model (Murchison and Rennison 2006) and are in line with the literature of monetary policy in open economies. ${ }^{14}$ We calibrate

\footnotetext{
${ }^{13}$ For the welfare analysis, we resort to a second-order approximation using the algorithm developed by Schmitt-Grohé and Uribe (2004b).

${ }^{14}$ For the elasticity of the investment adjustment cost, we chose the value $\mu_{S}=2.5$ taken from Christiano, Eichenbaum, and Evans (2005).
} 
Table 1. Baseline Parameter Values

\begin{tabular}{|c|c|c|}
\hline Description & Symbol & Value \\
\hline Discount Factor & $\beta$ & 0.99 \\
\hline Habit Persistence & $h$ & 0.65 \\
\hline Labor Supply Elasticity & $1 / \varphi$ & 0.60 \\
\hline $\begin{array}{l}\text { Share of Tradable Inputs_-Final } \\
\text { Goods Sector }\end{array}$ & $\alpha_{Y}$ & 0.50 \\
\hline $\begin{array}{l}\text { Elasticity of Substitution-Final } \\
\text { Goods Sector }\end{array}$ & $\eta_{Y}$ & 0.50 \\
\hline $\begin{array}{l}\text { Share of Home Inputs - Tradable } \\
\text { Goods Sector }\end{array}$ & $\gamma_{Y}$ & 0.50 \\
\hline $\begin{array}{l}\text { Elasticity of Substitution-Tradable } \\
\text { Goods Sector }\end{array}$ & $\omega_{Y}$ & 0.50 \\
\hline Depreciation Rate & $\delta$ & 0.02 \\
\hline Capital Share-Non-Tradable Sector & $\eta_{N}$ & 0.30 \\
\hline Labor Share-Non-Tradable Sector & $1-\eta_{N}$ & 0.70 \\
\hline Capital Share -Home Goods Sector & $\eta_{H}$ & 0.20 \\
\hline Labor Share-Home Goods Sector & $\gamma_{H}$ & 0.55 \\
\hline Learning Rate-Home Goods Sector & $\lambda_{H}$ & 0.25 \\
\hline $\begin{array}{l}\text { Calvo Parameter-Home Goods } \\
\quad \text { Sector }\end{array}$ & $\theta_{H}$ & 0.75 \\
\hline $\begin{array}{l}\text { Calvo Parameter-Non-Tradable } \\
\quad \text { Sector }\end{array}$ & $\theta_{N}$ & 0.75 \\
\hline $\begin{array}{l}\text { Elasticity of Substitution-Home } \\
\text { Goods Sector }\end{array}$ & $\varepsilon_{H}$ & 6 \\
\hline $\begin{array}{l}\text { Elasticity of Substitution- } \\
\text { Non-Tradable Sector }\end{array}$ & $\varepsilon_{N}$ & 6 \\
\hline Foreign Interest Rate Elasticity & $\left(\Theta^{\prime} / \Theta\right) B_{t}$ & 0.001 \\
\hline Foreign Demand Elasticity & $\eta^{*}$ & 0.50 \\
\hline $\begin{array}{l}\text { Depreciation Rate -Organizational } \\
\text { Capital }\end{array}$ & $1-\emptyset_{H}$ & 0.37 \\
\hline $\begin{array}{l}\text { Output Elasticity-Organizational } \\
\text { Capital }\end{array}$ & $\mu_{H}$ & 0.37 \\
\hline $\begin{array}{l}\text { Interest Rate Smoothing } \\
\text { Coefficient_-Taylor Rule }\end{array}$ & $\psi_{i}$ & 0.70 \\
\hline Inflation Coefficient-Taylor Rule & $\psi_{\pi}$ & 1.30 \\
\hline Output Coefficient-Taylor Rule & $\psi_{y}$ & 0.23 \\
\hline $\begin{array}{l}\text { Depreciation Coefficient-Taylor } \\
\quad \text { Rule }\end{array}$ & $\psi_{s}$ & 0.14 \\
\hline
\end{tabular}


the model so each time period is one quarter. The utility function is logarithmic in consumption with a constant labor supply elasticity:

$$
u\left(C_{t}-h \mathcal{H}_{t}, L_{t}\right)=\log \left(C_{t}-h \mathcal{H}_{t}\right)-\zeta_{L} \frac{L_{t}^{1+\varphi}}{1+\varphi},
$$

where $L_{t}$ is labor effort, $C_{t}$ is its total consumption, and the external habit component is defined by $\mathcal{H}_{t}=C_{t-1}$. Consistent with the evidence of Taylor (1999) and Nakamura and Steinsson (2008), we set the frequency of price adjustment to four quarters. In the baseline calibration, we assume that nominal rigidities are present in the home goods and non-tradable goods sectors. ${ }^{15}$

The Taylor-type rule parameters are obtained from Lubik and Schorfheide (2007). These authors use Bayesian techniques to estimate a specification of the Taylor rule for Canada in which the nominal interest rate responds to variations of GDP, inflation, and exchange rate depreciation, and has a smoothing component. Finally, the LBD parameters are obtained from Cooper and Johri (2002). The share of organizational capital in the production function is $\lambda_{H}=0.25$, which corresponds to a learning rate of 20 percent found in the literature. Consistent with the empirical evidence, the depreciation rate of organizational capital is $1-\phi_{H}=0.37$. Following Schmitt-Grohe and Uribe (2001), we assume that the elasticity of the risk premium with respect to debt is close to zero $\left(\Theta^{\prime} / \Theta\right) \mathcal{B}_{t}=0.001$, which induces stationarity without affecting the quantitative properties of the model.

Using data for Canada for the period 1981:Q1-2008:Q4, we estimate the following processes for the shocks affecting the economy:

$$
\begin{aligned}
a_{t}^{H} & =0.96 a_{t-1}^{T}+\epsilon_{t}^{H}, \epsilon_{t}^{H} \sim N\left(0, \sigma_{H}^{2}\right), \sigma_{H}=0.015, \\
a_{t}^{N} & =0.97 a_{t-1}^{N}+\epsilon_{t}^{N}, \epsilon_{t}^{N} \sim N\left(0, \sigma_{N}^{2}\right), \sigma_{N}=0.005, \\
x_{t} & =0.86 x_{t-1}+\epsilon_{t}^{X}, \epsilon_{t}^{X} \sim N\left(0, \sigma_{X}^{2}\right), \sigma_{X}=0.017,
\end{aligned}
$$

where $a_{t}^{H}, a_{t}^{N}$, and $x_{t}$ are the log-deviations of home goods sector productivity, non-tradable sector productivity, and production in

\footnotetext{
${ }^{15}$ In section 7 we also consider a model with incomplete exchange rate passthrough, where importers have the ability to set prices in the domestic market.
} 
the commodity sector (mining, gas, and oil). ${ }^{16}$ The commodity price shock and the external demand shock are estimated using data on oil prices and U.S. consumption:

$$
\begin{aligned}
p_{t}^{X}=0.94 p_{t-1}^{X}+\epsilon_{t}^{P X}, \epsilon_{t}^{P X} & \sim N\left(0, \sigma_{P X}^{2}\right), \sigma_{P X}=0.15, \\
c_{t}^{*}=0.99 c_{t-1}^{*}+\epsilon_{t}^{*}, \epsilon_{t}^{*} & \sim N\left(0, \sigma_{C^{*}}^{2}\right), \sigma_{C^{*}}=0.006,
\end{aligned}
$$

where $p_{t}^{X}$ and $c_{t}^{*}$ are the log-deviations of commodity prices and foreign consumption.

\section{Findings}

\subsection{Effects of Learning-by-Doing}

This section reports the quantitative effects of LBD in the economy. Figure 2 shows the impulse response function when the economy is affected by a transitory increase of one standard deviation of commodity prices. The solid lines represent the dynamics of a standard New Keynesian model without the LBD externality and the dashed lines represent the dynamics of the model laid out in section 2 including external LBD. Both models consider the same monetary policy rule with the parameters laid out in table 1 . To gain intuition about how shocks are propagated in the model, first we explain the dynamics of the small open economy without LBD and then the dynamics with this externality.

The solid lines in figure 2 show the reallocation process experienced in the economy in response to an increase of one standard deviation of commodity prices. Consistent with a standard two-sector model, the commodity shock induces a reallocation from the tradable sector to the non-tradable sector. In response to higher commodity prices, there is a higher demand for tradable and non-tradable goods. Considering that international prices of tradable goods are given, this higher demand for non-tradable goods will induce a real exchange rate appreciation and a reallocation of resources from the

\footnotetext{
${ }^{16}$ Even though our model allows for the possibility of stochastic shocks to the endowment of the commodity sector, in the simulation results shown in table 2 we shut down that shock. The difference in the simulations with and without endowment shocks is quantitatively small. The simulation of the model with the endowment shocks is available upon request.
} 


\section{Figure 2. Effects of Learning-by-Doing}
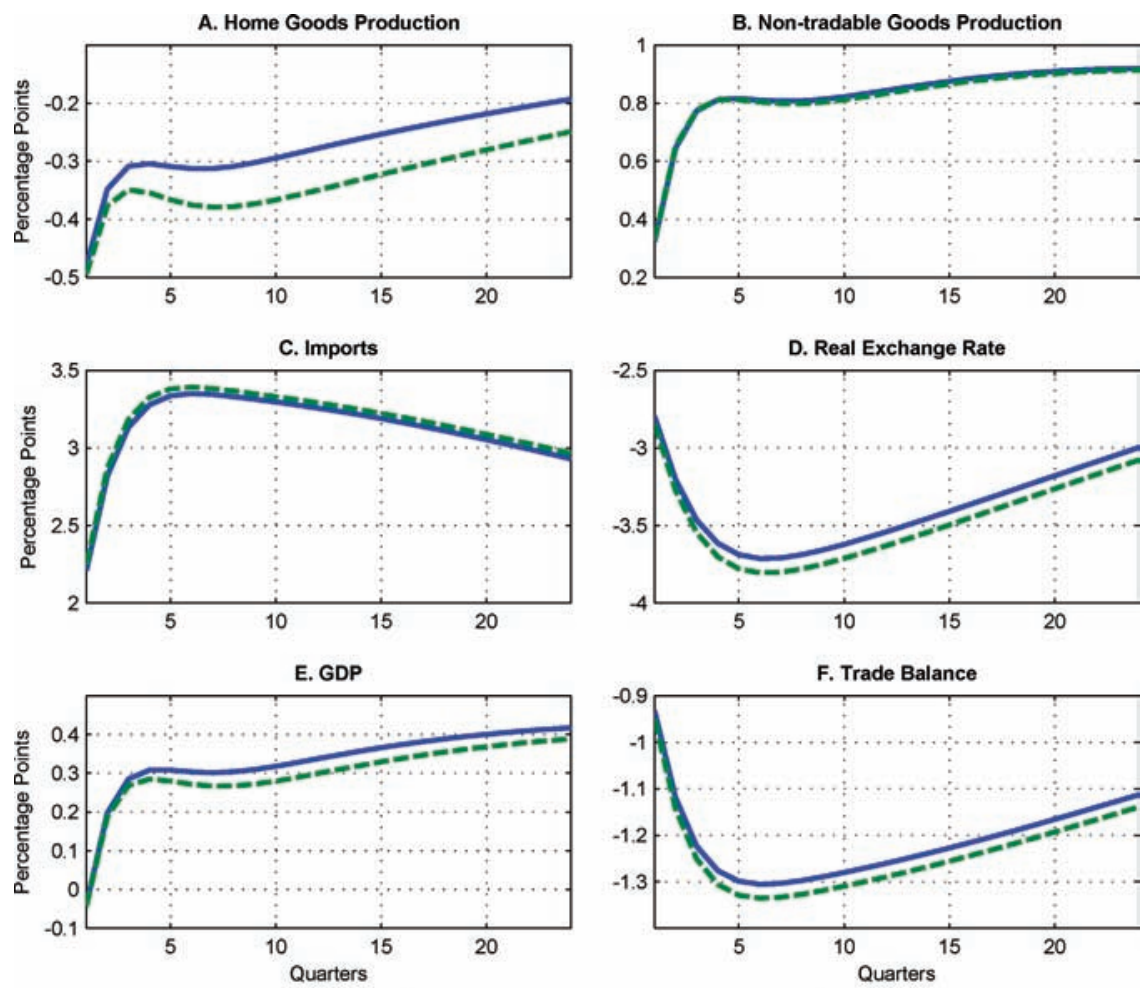

No LBD ---- LBD Externality

tradable to the non-tradable sector. At the same time, a higher demand for tradable goods is satisfied with imports from the rest of the world. As a result of the expansion of non-tradable production, GDP will increase, and as a consequence of lower tradable production and more imports, the trade balance deteriorates. ${ }^{17}$

The dashed lines in figure 2 describe the dynamics of the model with LBD. Two effects are operating in the model with LBD. First, in response to a decline in home goods production, the amount of organizational capital decreases through the law of motion (10).

\footnotetext{
${ }^{17}$ In the impulse response function, we show the trade balance excluding the commodity exports to better assess the effects of higher commodity prices.
} 
A lower organizational capital reduces the overall productivity of the home goods sector, which exacerbates the initial contraction in production, as shown in panel A. Second, lower productivity in the home goods sector increases the price level in the small open economy, which leads to a higher value of the real exchange rate, as shown in panel D. As we can appreciate in panels $\mathrm{E}$ and F, lower production of home goods and a further real exchange rate appreciation leads to smaller expansion of GDP and a further deterioration of the trade balance.

Overall, the main effects of LBD in the model are a decline of tradable production, GDP, and the trade balance. Clearly, this externality reduces welfare of households. In the next sections we evaluate how successful a policy of exchange rate stabilization is in correcting this externality.

\subsection{Learning-by-Doing and Exchange Rate Stabilization}

In this section we evaluate the impact of alternative policy rules to correct the frictions associated with price rigidities and the LBD externality. We consider three types of monetary policy rules which differ in their degree of exchange rate intervention: the empirical monetary policy rule, a monetary policy rule with no exchange rate intervention, and a fixed exchange rate policy. For the first rule we use the baseline calibration summarized in table 1 . The empirical estimates from Lubik and Schorfheide (2007) indicate a moderate amount of exchange rate intervention, given the parameter value $\psi_{s}=0.14$. In addition to this baseline calibration, we consider two polar cases: first, the case of no intervention, in which $\psi_{s}=0$, and second, the case of a fixed exchange rate regime, where $\psi_{s} \longrightarrow \infty$.

We compare the dynamics of these rules with the allocations of a benchmark model with flexible prices and internalized LBD. ${ }^{18}$ When LBD is internalized, there is a price for organizational capital that allows firms and households in the economy to decide the efficient amount of employment, physical capital, organizational capital, and production for the sector. The real allocation of the benchmark model indicates the best outcome a policy intervention can achieve

\footnotetext{
${ }^{18}$ See appendix 2 for the first-order conditions of the benchmark model with flexible prices and internalized learning-by-doing.
} 
at business-cycle frequencies. ${ }^{19}$ Any discrepancy or deviation from the benchmark model indicates a misallocation of resources in the economy. We gauge if a particular monetary policy rule is welfare improving if it is able to close the discrepancies or gaps with the benchmark frictionless model. In the limit, the optimal policy will generate an allocation that exactly coincides with the one from the benchmark model. ${ }^{20,21}$

Figure 3 shows the impulse response function for the real allocations of the benchmark model and three rules: the empirical rule, a monetary rule with no exchange rate intervention, and a fixed exchange rate. For the benchmark model, we observe a reallocation of resources from the home goods sector to the non-tradable sector. Notice that even though the LBD externality is internalized, it is optimal to allow for a contraction of the home goods sector. In the benchmark model, we also observe an appreciation of the real exchange rate and an expansion of GDP. To evaluate the success of alternative policy rules, we have to measure how far from this benchmark are the allocations generated by the alternative monetary policy rules.

First we analyze the behavior of the monetary rule with no exchange rate intervention $\left(\psi_{s}=0\right)$. Under this rule, home goods production goes below the efficient level of output. In terms of the New Keynesian literature, under this rule there is a negative output gap in the home goods production. In principle, it is possible to close this gap by engineering a monetary expansion that depreciates the exchange rate and stimulates tradable output. However, it is important for policymakers to evaluate what are the implications of an exchange rate depreciation in other sectors of the economy.

\footnotetext{
${ }^{19}$ An additional friction we consider in the model is monopolistic competition, which generates a misallocation of resources at the steady state. Goodfriend and King (2001) showed that monetary policy is not effective to remove the markup of monopolistic competition at the steady state. If we additionally consider a subsidy on employment, then it is possible to achieve the first-best allocation with the combination of fiscal and monetary policy.

${ }^{20}$ See Correia, Nicolini, and Teles (2008).

${ }^{21}$ If we evaluate a variable such as production, a deviation with respect to the benchmark model is consistent with the definition of output gap in a standard New Keynesian model.
} 


\section{Figure 3. Learning-by-Doing and Exchange Rate Stabilization}
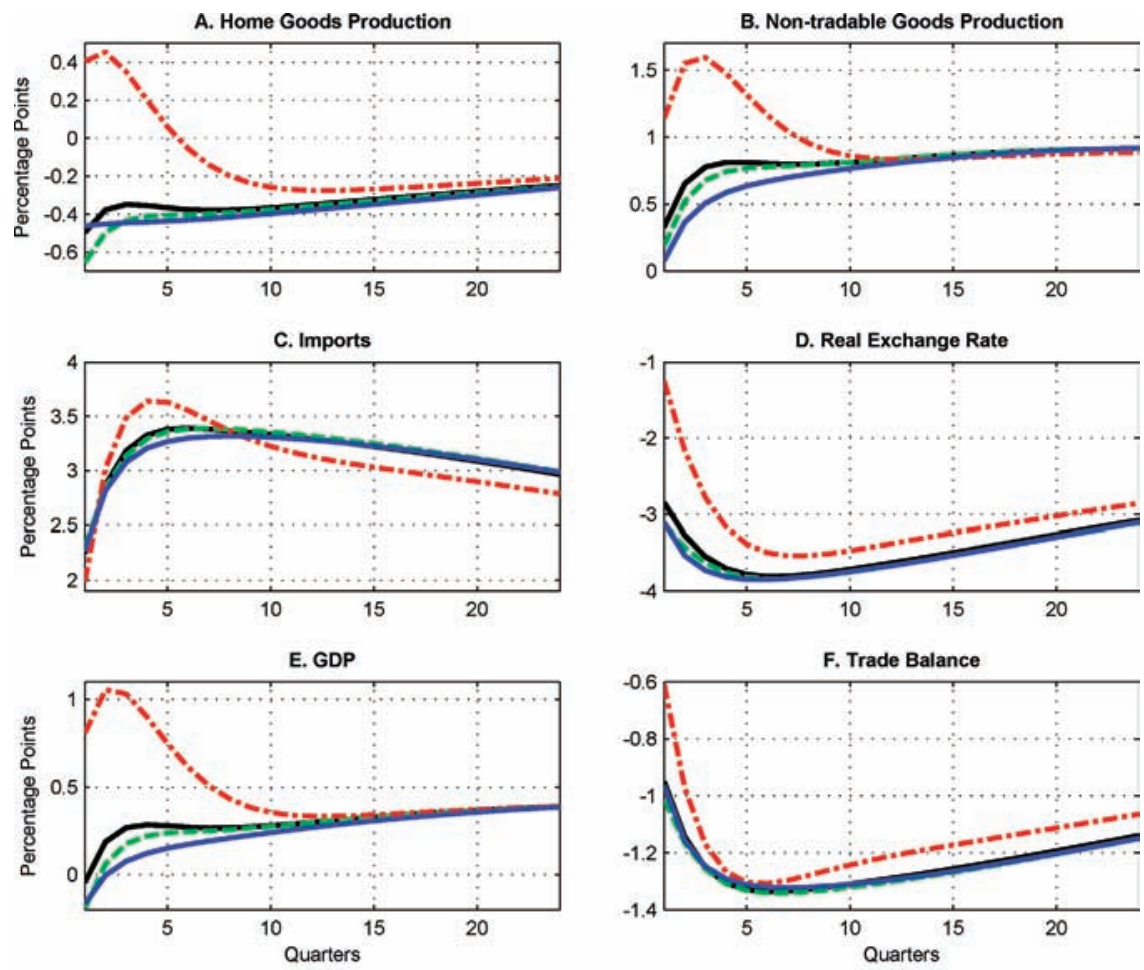

Empirical Rule - - No Intervention - - N- Fixed Exchange Rate

Real Allocation

Now we consider the empirical rule which considers some exchange rate intervention, that is, $\psi_{s}=0.14$. This parameter reduces the appreciation of the real exchange rate in response to the commodity price shock. The empirical rule allows the production of home goods to be closer to the efficient level; however, the rest of the sectors are going to expand more than in the benchmark model. Figure 3 shows how non-tradable production and imports are larger than the efficient level, while the real exchange rate is going to be more depreciated. In addition, GDP increases more than the efficient level.

The third rule is a fixed exchange rate, which sets $\psi_{s} \rightarrow \infty$. Given that we consider sticky prices in the model economy, this policy is extremely successful in limiting the magnitude of exchange 
rate appreciation in the short run. Nevertheless, all the quantities in the small open economy overshoot the allocations compared with the benchmark model, which reflects higher distortions. In sum, this policy generates higher macroeconomic volatility and welfare costs compared with other rules.

There are two main results from this section. First, monetary policy is a very potent instrument to increase tradable production and to prevent an inefficient outcome in this sector. Second, leaning against an appreciated exchange rate generates greater macroeconomic volatility, measured by the deviations from the efficient allocation. The initial impulse of higher commodity prices triggers an expansion of aggregate demand in a commodity-exporting economy like Canada. In this situation, a policy of exchange rate stabilization generates a further expansion of aggregate demand and greater volatility over the business cycle. To evaluate whether or not this is an appropriate policy, we need to compare the benefits of higher tradable production against the costs of larger macroeconomic volatility. In the next section we conduct a welfare analysis of alternative policy rules to compare properly the costs and benefits of stabilizing the exchange rate during a Dutch disease episode.

\section{Business Cycles and Welfare Calculations}

This section quantifies the welfare costs of alternative monetary policy rules. The welfare costs are calculated as in Lucas (1987) and are measured as a fraction of consumption that agents are willing to give up to eliminate the excess volatility of a specific policy. The welfare of the benchmark model with flexible prices and internalized LBD, denoted by $B$, and the welfare of a monetary regime, denoted by $R$, are given by

$$
\begin{aligned}
& U^{B}=E\left[\sum_{t=0}^{\infty} \beta^{t} u\left(C_{t}^{B}-h C_{t-1}^{B}, 1-L_{t}^{B}\right)\right], \\
& U^{R}=E\left[\sum_{t=0}^{\infty} \beta^{t} u\left(C_{t}^{R}-h C_{t-1}^{R}, 1-L_{t}^{R}\right)\right] .
\end{aligned}
$$

Typically (26) is going to be greater than (27) since the benchmark model does not incorporate frictions such as price stickiness 
Table 2. Simulated Business Cycles and Welfare Costs

\begin{tabular}{|l|c|c|c|c|c|c|c|}
\hline & \multicolumn{3}{|c|}{ Std. Dev. } & \multicolumn{3}{|c|}{$\begin{array}{c}\text { Std. Dev. } \times / \text { Std. } \\
\text { Dev. GDP }\end{array}$} & Welfare \\
\cline { 2 - 8 } & GDP & NX/GDP & C & INV & L & RER & $\lambda$ \\
\hline Canadian Data & 1.51 & 0.89 & 0.57 & 2.73 & 0.71 & 2.46 & - \\
$\quad$ (1981-2008) & & & & & & & \\
Empirical Rule & 1.49 & 0.93 & 0.78 & 2.65 & 0.76 & 2.81 & 0.04 \\
No Intervention & 1.58 & 1.32 & 0.77 & 2.70 & 0.79 & 2.97 & 0.04 \\
Fixed Exchange Rate & 2.52 & 1.22 & 0.79 & 2.49 & 0.98 & 1.50 & 0.19 \\
\hline
\end{tabular}

and LBD externality. In order to evaluate how costly is a specific policy, we solve for the welfare cost, denoted by $\lambda$, in the following equation:

$$
\begin{aligned}
& E\left[\sum_{t=0}^{\infty} \beta^{t} u\left((1-\lambda)\left(C_{t}^{B}-h C_{t-1}^{B}\right), 1-L_{t}^{B}\right)\right] \\
= & E\left[\sum_{t=0}^{\infty} \beta^{t} u\left(C_{t}^{R}-h C_{t-1}^{R}, 1-L_{t}^{R}\right)\right] .
\end{aligned}
$$

The welfare cost is computed as in Schmitt-Grohé and Uribe (2005) from the second-order approximation of equation (28). If a specific policy generates welfare costs, then $\lambda>0$, while if it is successful to correct nominal rigidities and the LBD externality, then $\lambda=0$. To have a meaningful estimation of the welfare costs, first we ensure that the model is able to reproduce some of the moments in the data. Table 2 describes the second moments from the data and the model, as well as the welfare costs of monetary policy rules.

The first row in table 2 reports some moments observed in the Canadian data. We observe that consumption and employment are less volatile than GDP, while investment and the real exchange rate are about twice as volatile as output. The fact that consumption is less volatile than GDP is not specific to Canada but is a feature common to industrialized countries. ${ }^{22}$ On the other hand, investment

\footnotetext{
${ }^{22}$ See Neumeyer and Perri (2005) and Aguiar and Gopinath (2007).
} 
tends to be more volatile than output in most small open economies, both industrialized and emerging. ${ }^{23}$

The second row in table 2 shows the results from simulating the model with the calibrated empirical rule subject to the five shocks described in section 3 . Overall, the model with the empirical rule matches the main features of the data. In the model, consumption tends to be more volatile than in the data, but it is still the case that consumption is less volatile than GDP, as is observed in developed small open economies. The last column in the second row shows the welfare cost as a fraction of the steady consumption. The empirical rule generates a welfare cost equivalent to 0.04 percent of lifetime consumption.

The third row shows the second moments and welfare calculation of the Taylor-type rule with no exchange rate intervention. The results of this policy are very close to the empirical rule; however, this Taylor-type rule allows for greater real exchange rate volatility. This volatility spills over the trade balance, which has a standard deviation 50 percent larger than in the case of the empirical rule. In this case we also obtain welfare costs that are similar to the ones obtained from the empirical rule, indicating that the allocations are not quantitatively different among these policies.

The fourth row shows the fixed exchange rate policy. This rule increases the volatility of GDP by 60 percent and the volatility of labor by 25 percent, and at the same time reduces real exchange rate volatility by 50 percent. ${ }^{24}$ As we analyzed in the previous section, stabilizing the nominal exchange rate in response to an increase in commodity prices can be achieved by increasing money supply. This policy provides a further stimulus to the economy, in addition to an increase in commodity prices, increasing output volatility and reducing households' welfare. The welfare cost of this policy is equivalent to 0.19 percent of lifetime consumption. This number is about two times the measure of costs of business cycles estimated by Lucas (1987). This welfare loss is generated mainly by the increase in labor supply volatility by 25 percent.

\footnotetext{
${ }^{23}$ See Schmitt-Grohé (1998).

${ }^{24}$ Notice that since investment responds sluggishly owing to the investment adjustment costs, most of the GDP variation in the short run is generated by fluctuations of labor and productivity.
} 


\section{Figure 4. Welfare Costs and Exchange Rate Stabilization}
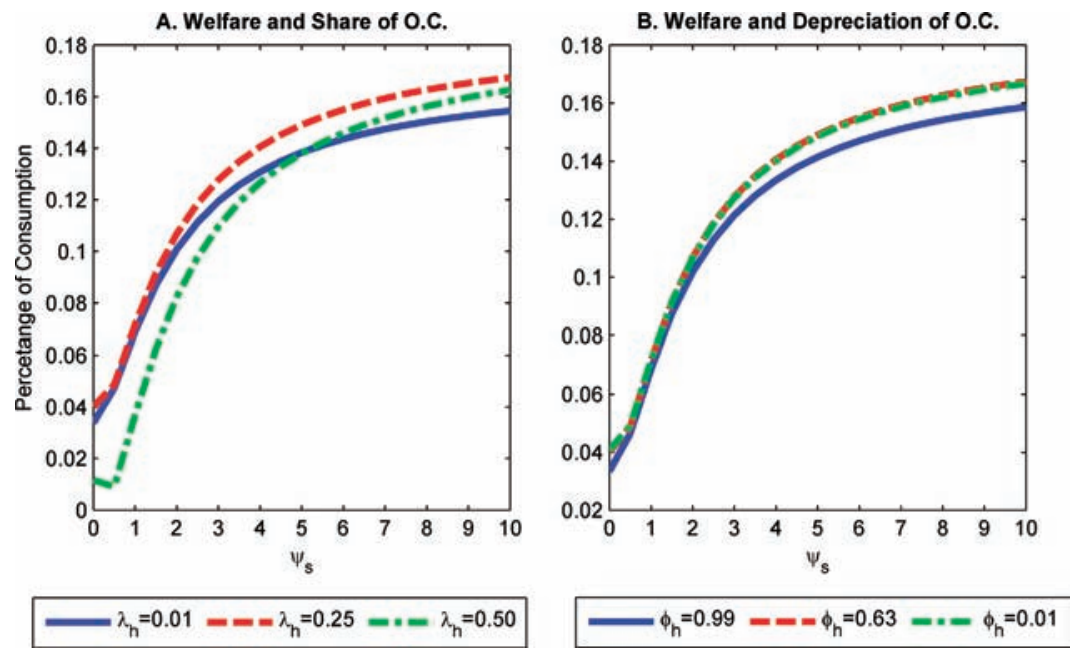

Figure 4 depicts the welfare costs as a function of the exchange rate intervention parameter $\psi_{s}$. The horizontal axis shows the depreciation rate coefficient in the Taylor rule, and the vertical axis shows the welfare costs measured by $\lambda$. This welfare analysis allows us to better understand the welfare costs of exchange rate stabilization for a wider spectrum of monetary rules.

In panel A we consider three assumptions for the share of organizational capital: the baseline calibration in which $\lambda_{H}=0.25$, then a case of a low share, $\lambda_{H}=0.01$, and finally the case of a high share in which $\lambda_{H}=0.50$. For the baseline calibration and the case of a low share, welfare costs are an increasing function of exchange rate intervention. As a central bank intervenes in the foreign exchange rate market, the allocation in the economy tends to move away from the efficient equilibrium, which is costly in terms of welfare. In particular, a policy of exchange rate stabilization increases macroeconomic volatility, which affects negatively households' welfare. Only when the amount of LBD externality is twice the magnitude of the empirical estimations $\left(\lambda_{H}=0.50\right)$ are there some gains derived from moderate exchange rate interventions. ${ }^{25}$ When the exchange rate

\footnotetext{
${ }^{25}$ See Cooper and Johri (2002).
} 
stabilization coefficient $\psi_{s}$ is below 1 , then the benefits from protecting the tradable sector outweigh the costs of higher macroeconomic volatility, generating a reduction in welfare costs. When the coefficient is greater than 1, the opposite case holds, and the costs of macroeconomic volatility exceed any potential gain of stabilizing the tradable sector.

In panel $\mathrm{B}$ we evaluate alternative assumptions on the depreciation rate: the baseline case of $\phi_{H}=0.63$, the case of low depreciation rate $\phi_{H}=0.99$, and finally the case of high depreciation rate $\phi_{H}=0.01{ }^{26}$ For the three assumptions of depreciation rate, the more aggressive is the monetary policy rule to stabilize the nominal exchange rate, the larger are the welfare costs. Even though the depreciation rate affects the persistency of the externality over time, it does not change the main conclusion of table 2: more exchange rate intervention increases macroeconomic volatility and the welfare costs of the representative household.

The main result in this section is that a policy of exchange rate intervention typically results in welfare losses. In spite of being an effective instrument to correct inefficiencies in the home goods sector, the policy is costly in terms of macroeconomic volatility. This result suggests that correcting the LBD externality with monetary policy is highly distortionary for empirically plausible estimates of the LBD externality. On the other hand, allowing an exchange rate appreciation during a Dutch disease episode ensures an efficient allocation of resources across sectors. This result is consistent with the view of Friedman (1953) in favor of flexible exchange rates. In presence of nominal rigidities, a flexible exchange rate is capable of insulating the economy from external shocks by generating a faster adjustment of relative prices.

\section{Optimal Fiscal and Monetary Policy Rules}

In the previous sections we evaluated the impact of increasing the extent of exchange rate stabilization on the resource allocation in a small open economy. The main conclusion from the quantitative analysis is that protecting the tradable sector with monetary

\footnotetext{
${ }^{26}$ Recall that in the model the depreciation rate is given by $\left(1-\phi_{H}\right)$.
} 
policy results in reduction in welfare and an increase in macroeconomic volatility. Then, the natural question is: what policies are appropriate to cope with Dutch disease episodes? In this section we evaluate fiscal and monetary policy rules that can improve the allocation of resources during a commodity boom. The fiscal rule is a state-contingent subsidy rule $\left(\tau_{t}^{H}\right)$ on the production of home goods designed to correct the LBD externality:

$$
\tau_{t}^{H}=E_{t}\left[f\left(x_{t}, x_{t+1}, y_{t}, y_{t+1}\right)\right]
$$

where $x_{t}$ and $y_{t}$ are the vectors of predetermined and jump variables in the model, respectively. In appendix 2 we show the derivation of the optimal subsidy rule. For the monetary policy rule we use the same specification as in (14) and choose the coefficients of the rule that maximize the unconditional welfare of the representative household. The resulting coefficients of the optimized Taylor-type rule are given by $\psi_{\pi}=2.23, \psi_{i}=0.56, \psi_{y}=-0.76$, and $\psi_{s}=-0.25 .^{27}$

The coefficients on GDP and exchange rate depreciation in the optimized rule have negative signs, which are not consistent with the empirical estimates. Ireland (1996) provides an explanation regarding the existence of a negative GDP coefficient on the optimized rule. He shows that in models with nominal rigidities and productivity shocks, the optimal monetary policy is procyclical. ${ }^{28}$ In the context of our model, the presence of productivity shocks driving the business cycle leads to a negative relationship between output and the short-term rate in the optimal rule. Schmitt-Grohé and Uribe (2004a) also show that expressing the optimal monetary policy in terms of a Taylor-type rule leads to a negative coefficient on output.

In order to gain more intuition about the optimal coefficient on exchange rate intervention, it is convenient to analyze the loglinearized version of the Taylor-type rule:

$$
\widehat{i}_{t}=\psi_{i} \widehat{i}_{t-1}+\left(1-\psi_{i}\right)\left(\psi_{y} \widehat{y}_{t}+\psi_{\pi} \hat{\pi}_{t}+\psi_{s} \widehat{s}_{t}\right),
$$

\footnotetext{
${ }^{27}$ Schmitt-Grohé and Uribe (2007) show that an optimized rule of this form generates dynamics that approximate the Ramsey policy.

${ }^{28}$ Since an increase in productivity reduces prices, the optimal policy increases the money supply in order to stabilize the price level, resulting in a procyclical monetary policy.
} 
where the variable $\widehat{x}_{t}$ denotes the logarithmic deviations of the variable $x_{t}$ from its steady state $\bar{x}$, that is, $\widehat{x}_{t}=\log \left(x_{t}\right)-\log (\bar{x})$. In equation (30) $\widehat{i}_{t}, \widehat{y}_{t}, \hat{\pi}_{t}$, and $\widehat{s}_{t}$ denote the logarithmic deviations of the gross nominal interest rate, GDP, CPI inflation, and nominal exchange rate depreciation, respectively. In addition, the CPI inflation in log-linear form is defined as

$$
\hat{\pi}_{t}=\alpha_{Y}\left(\left(\gamma_{Y}\right) \hat{\pi}_{t}^{H}+\left(1-\gamma_{Y}\right) \widehat{s}_{t}\right)+\left(1-\alpha_{Y}\right) \hat{\pi}_{t}^{N} .
$$

Adopting the parameter values from the baseline calibration, we get the following expressions:

$$
\begin{gathered}
\widehat{i}_{t}=0.56 \widehat{i}_{t-1}+(1-0.56)\left(-0.76 \widehat{y}_{t}+2.23_{t} \hat{\pi}_{t}-0.25 \widehat{s}_{t}\right) \\
\hat{\pi}_{t}=0.5 \hat{\pi}_{t}^{N}+0.25 \hat{\pi}_{t}^{H}+0.25 \widehat{s}_{t} .
\end{gathered}
$$

Finally, combining (33) and (32), we get the expression for the optimal monetary policy rule:

$$
\widehat{i}_{t}=0.56 \widehat{i}_{t-1}+(1-0.56)\left(-0.76 \widehat{y}_{t}+1.12_{t} \hat{\pi}_{t}^{N}+0.56_{t} \hat{\pi}_{t}^{H}+0.31 \widehat{s}_{t}\right) .
$$

In equation (34) we observe that in fact the optimized rule allows some exchange rate stabilization. This policy rule implies a larger exchange rate volatility compared with a monetary policy rule that targets exclusively CPI inflation. Even though in the initial optimized rule (32) a central bank might be seen as "leaning with the wind," in practice it is focusing on exchange rate stabilization, giving a weight of 0.31 to exchange rate depreciation in the alternative rule (34).

In figure 5 we analyze the dynamics of the optimized monetary policy rule and we compare it against two benchmarks: a frictionless model with flexible prices and internalized LBD and the full-blown model with a non-tradable inflation-targeting rule that sets the nontradable inflation to the steady-state level $\pi_{t}^{N}=\bar{\pi}^{N}$. Similar to the exercise conducted in section 4 , the frictionless model indicates the best possible outcome that a policy intervention can achieve.

Figure 5 shows that the dynamics of the model under the optimized rule tracks fairly well the allocations obtained from the real allocation of the frictionless model. Two variables show significant 


\section{Figure 5. Optimal Fiscal and Monetary Policy Rules}
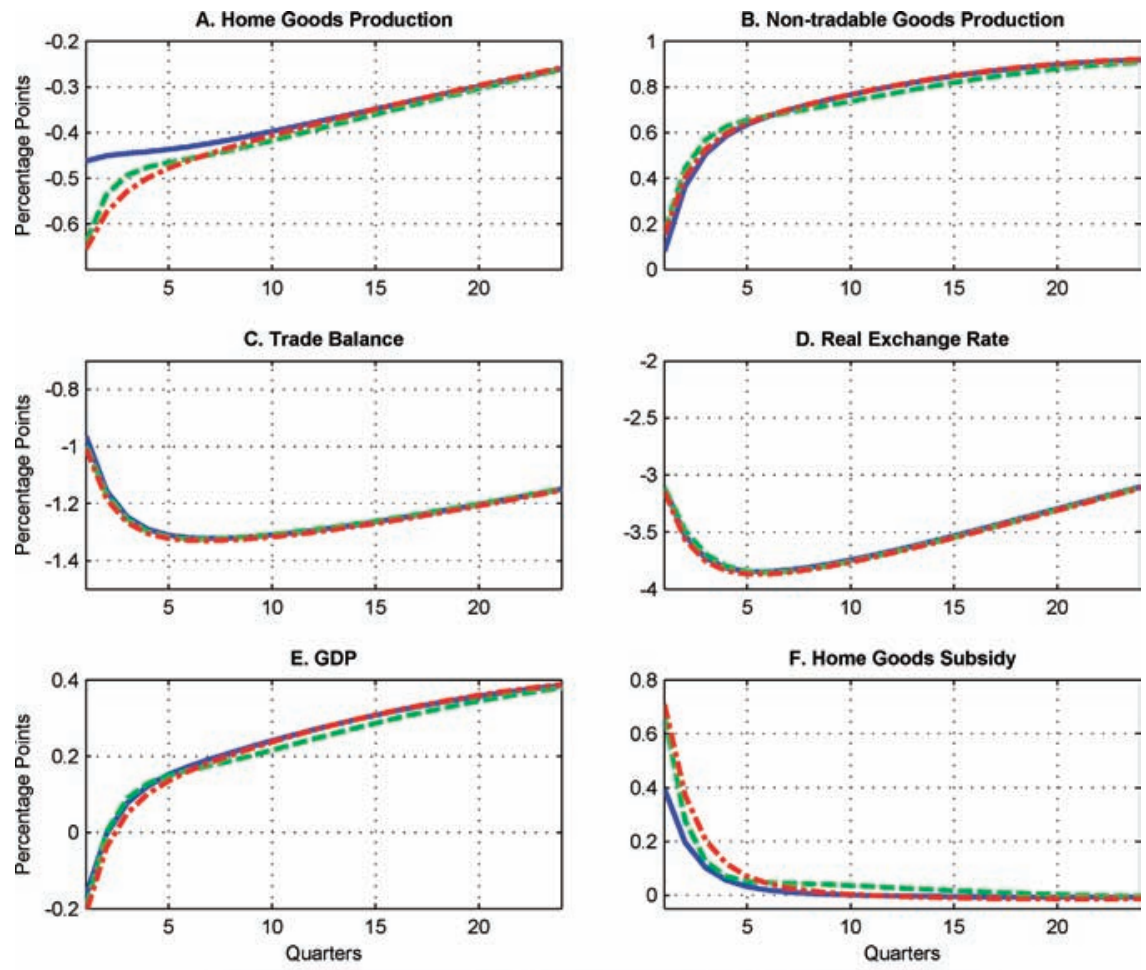

Real Allocation -- Optimized Rule $=\cdot-*-$ NT Inflation Targeting

departures from the frictionless model: the home goods production and the optimal subsidy, shown in panels A and F. Home goods production experiences a larger contraction under the optimized rule compared with the frictionless economy. On the other hand, the subsidy is much higher compared with the efficient case.

The key difference between the home goods production in the model with the optimized rule and in the frictionless model is the presence of nominal rigidities in that sector. ${ }^{29}$ This discrepancy indicates that the optimized monetary policy rule is less focused on

\footnotetext{
${ }^{29}$ The optimal subsidy shown in panel $\mathrm{G}$ is correcting the LBD externality, so the discrepancy between the dynamics of the model with the optimized rule and the frictionless model can be attributed to the presence of nominal rigidities.
} 
correcting the problem of nominal rigidities in the tradable sector. To better understand why the optimized rule is not stabilizing the tradable sector, it is useful to compare its performance with the non-tradable inflation-targeting rule.

The non-tradable inflation stabilizes the markup in the nontradable sector and ensures a flexible price allocation in that particular sector. ${ }^{30}$ In figure 6 we can notice that the non-tradable inflation targeting tracks very closely the optimized rule. The reason for the similarity is that the optimized rule focuses on stabilizing the largest sector exposed to nominal rigidities. In the baseline calibration, the lion's share of production is concentrated in the non-tradable sector, and the frequency of price adjustment is the same across sectors, hence the optimized rule will give a higher weight to stabilizing non-tradable inflation. ${ }^{31}$ For our particular calibration, the dynamics of the optimized rule are not quantitatively different from the non-tradable inflation-targeting rule.

Finally, in panel $\mathrm{F}$ we observe that the optimal subsidy is larger both under the optimized rule and the non-tradable inflationtargeting rule. This can be explained by the fact that there is an additional contraction of tradable output under the optimized rule, which exacerbates the LBD externality. In this case, since the optimal fiscal rule is designed to remove the effects from LBD, there is an increase in the subsidy to expand tradable production and correct the externality. In equilibrium, it is still the case that tradable production drops below the efficient level due to the presence of nominal rigidities.

The results from this section complement the findings in the previous sections. In response to an increase in commodity prices, the optimal fiscal and monetary policy rules allow a real exchange rate appreciation and a reallocation between tradable and non-tradable goods. Any policy that prevents this reallocation process will result in a reduction of welfare.

\footnotetext{
${ }^{30}$ For an evaluation of the non-tradable inflation-targeting rule, see Lama and Medina (2011).

${ }^{31}$ Benigno (2004) makes a similar argument. In a currency union, if two countries have the same frequency of price adjustment, the optimal monetary policy for the union will stabilize a weighted average of regional inflation rates, where the weights are determined by the size of each country.
} 


\section{Figure 6. Model Extensions}
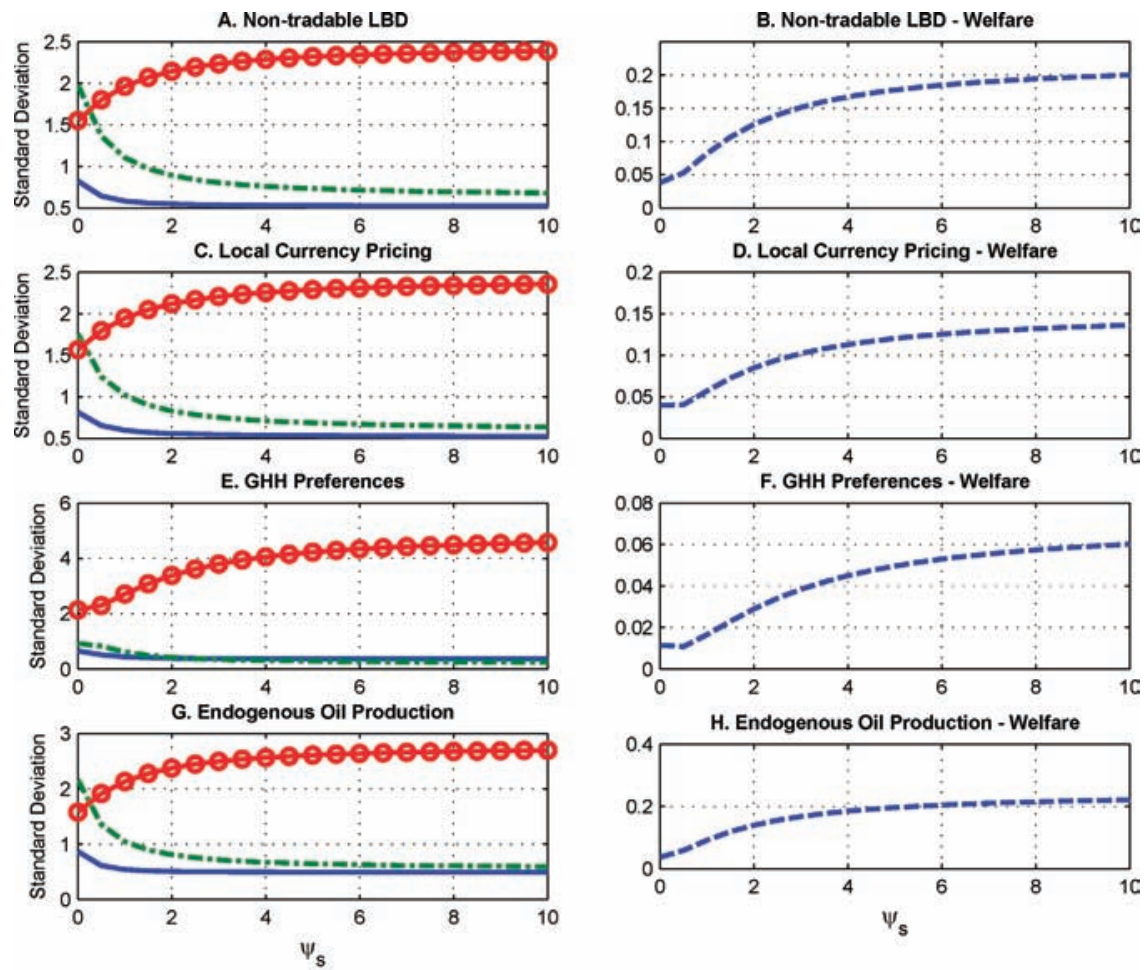

- Home Goods $-\cdot \cdot \cdot-$ RER $-\mathrm{O}-\mathrm{GDP}$

\section{Model Extensions}

Now we consider alternative specifications of the model to assess the robustness of our results. There are several dimensions in which we could add more layers of realism to the model. In this section we explore four modifications to the small open-economy model: LBD in the non-tradable sector, local currency pricing (LCP), GHH preferences, and endogenous oil production. All of these frictions are commonly discussed in the literature and potentially can improve the fit of the model to the data. For each of these specifications we show the volatility of GDP, the volatility of home goods production, and the real exchange rate relative to GDP and the welfare cost as a function of the parameter $\psi_{s}$, which measures the extent of 
exchange rate stabilization. Figure 6 shows the results for all model extensions.

\subsection{Non-Tradable Learning-by-Doing}

In the baseline model we assume a standard Cobb-Douglas production in the non-tradable sector. In this extension we introduce LBD in the non-tradable sector with the following specification:

$$
\begin{gathered}
Y_{t}^{N}(h)=A_{t}^{N}\left[H_{t}^{N}(h)\right]^{\lambda_{N}}\left[K_{t}^{N}(h)\right]^{\eta_{N}}\left[L_{t}^{N}(h)\right]^{\gamma_{N}}, \\
H_{t+1}^{N}(h)=\left[H_{t}(h)\right]^{\phi_{N}}\left[\bar{Y}_{t}^{N}\right]^{\mu_{N}},
\end{gathered}
$$

where $A_{t}^{N}, K_{t}^{N}(h), H_{t}(h), \bar{Y}_{t}^{N}$, and $L_{t}^{N}(h)$ denote an aggregate productivity shock, physical capital, organizational capital, aggregate non-tradable production, and labor, respectively. We assume the same parameter values of LBD in the home goods and nontradable goods sectors. Panels A and B in figure 6 show the effects of exchange rate stabilization. While stabilizing the nominal exchange rate reduces the volatility of the real exchange rate and the production of home goods, it increases the volatility of the GDP. Qualitatively, the results are similar to the initial model specification: more exchange rate intervention stabilizes the tradable sector but at the expense of higher volatility and welfare costs.

It is important to notice that in the presence of LBD externalities in the non-tradable sector, there are welfare gains from an exchange rate appreciation. An appreciated exchange rate stimulates the production of non-tradable goods and, through the LBD mechanism, it leads to more organizational capital and more productivity and production in the future. In this situation, stabilizing the nominal exchange rate generates further welfare costs, since it prevents the potential productivity gains stemming from the LBD externality in the non-tradable sector. In panel $\mathrm{B}$, the welfare cost of a more aggressive exchange rate intervention leads to higher welfare costs compared with the costs shown in figure 4 for the baseline model.

\subsection{Local Currency Pricing}

In the baseline model we considered the case of full pass-through from exchange rate to import prices. In practice, it takes some time 
before nominal exchange rate variations are fully incorporated into import prices, so we evaluate the implications of assuming LCP on imports. ${ }^{32}$ Under this assumption, every period a fraction $\left(1-\theta_{M}\right)$ of importers set their prices optimally. The optimal price $P_{t}^{M *}(j)$ chosen by each importer maximizes the expected present value of profits:

$$
E_{t}\left[\sum_{i=0}^{\infty}\left(\theta_{M}\right)^{i} \Lambda_{t, t+i}\left(\frac{P_{t}^{M *}(j)-\mathcal{E}_{t+i} P_{t+i}^{D}}{P_{t+i}^{M}}\right) Y_{t+i}^{M}(j)\right],
$$

where $\Lambda_{t, t+i}$ is the stochastic discount factor, $P_{t}^{D}$ is the foreign price of the imported goods at the dock, and $\mathcal{E}_{t+i}$ is the nominal exchange rate. The term $\mathcal{E}_{t+i} P_{t+i}^{D}$ is the price of imported goods at the dock expressed in domestic currency. The price stickiness parameter is set to $\theta_{M}=0.75$.

The direct consequence of introducing LCP in the model is a reduction of real exchange rate fluctuations. With limited exchange rate pass-through, CPI inflation will be less volatile, and hence there will be reduced volatility of the real exchange rate. As we notice in panel $\mathrm{C}$, real exchange rate volatility is lower than the one calculated in the baseline model for any value of $\psi_{s}$. On the other hand, as suggested by Devereux and Engel (2003), under LCP there are some welfare gains from stabilizing the nominal exchange rate. In the context of our model, panel D shows that the welfare costs are lower than in the baseline case, indicating some benefits from stabilizing the nominal exchange rate to correct the LCP friction. However, in this model specification, the overall effect of exchange rate intervention results in positive welfare costs due to the presence of nominal rigidities in the home and non-tradable goods sectors.

\subsection{GHH Preferences}

The baseline model is solved for preferences that are separable on labor and consumption. An alternative specification is with GHH preferences proposed by Greenwood, Hercowitz, and Huffman (1988). These preferences are commonly used in small open-economy

\footnotetext{
${ }^{32}$ For a DSGE estimation of models with local currency pricing, see Rabanal and Tuesta (2010).
} 
models and are characterized by the non-separability of consumption and labor and the suppression of the wealth effect in the labor supply decision. The GHH momentary utility function takes the following specification:

$$
u\left(C_{t}-h \mathcal{H}_{t}, L_{t}\right)=\log \left(C_{t}-h \mathcal{H}_{t}-\frac{\zeta_{L}}{1+\varphi} L_{t}^{1+\varphi}\right) .
$$

Neumeyer and Perri (2005) show that the non-separability between consumption and leisure increases the volatility of consumption in a standard small open-economy model. In panels $\mathrm{E}$ and $\mathrm{F}$ we observe that the higher consumption volatility introduced by these preferences generates higher GDP volatility compared with the baseline model. Under these preferences the main result of the paper is robust, and a more aggressive policy of exchange rate stabilization increases macroeconomic volatility and results in higher welfare costs.

\subsection{Endogenous Commodity Production}

The baseline specification considers the case in which the extraction of commodities is modeled as a stochastic process. A more realistic assumption is to consider a production process in which labor and capital are employed. In particular, we adopt the following CES production function for commodities $\left(Y_{t}^{C}\right)$ :

$$
\begin{aligned}
Y_{t}^{C}= & A_{t}^{C}\left[\alpha_{C}^{1 / \eta_{C}}\left(K_{t}^{C}\right)^{\frac{\eta_{C}-1}{\eta_{C}}}+\left(\gamma_{C}\right)^{1 / \eta_{C}}\left(L_{t}^{C}\right)^{\frac{\eta_{C}-1}{\eta_{C}}}\right. \\
& \left.+\left(1-\alpha_{C}-\gamma_{C}\right)^{1 / \eta_{C}}\left(X_{t}\right)^{\frac{\eta_{C}-1}{\eta_{C}}}\right]^{\frac{\eta_{C}}{\eta_{C}-1}}
\end{aligned}
$$

where $K_{t}^{C}, L_{t}^{C}, X_{t}$, and $A_{t}$ are the stock of physical capital, labor, natural resources, and productivity, respectively. We calibrate the share of each input in the production function according to the work of de Resende, Dib, and Kichian (2010) and set $\alpha_{C}=\gamma_{C}=0.4$. In addition, we assume an elasticity of substitution across inputs $\left(\eta_{C}\right)$ of 0.5 . The consequence of adopting a more general production function for commodities is that in order to expand production, commodity-producing firms will have to absorb workers from other 
sectors in the economy. In particular, in response to a reallocation process of labor across sectors, we will expect to see a higher volatility of home goods production. In panels $\mathrm{G}$ and $\mathrm{F}$ we observe that the volatility of home goods production is higher compared with other cases, although the difference is not quantitatively significant. Similar to the previous model extensions, we observe that a higher degree of exchange rate stabilization leads to higher GDP volatility and additional welfare costs.

\section{Conclusions}

In this paper we evaluated the consequences of stabilizing the nominal exchange rate in response to a Dutch disease episode. In order to evaluate this policy intervention, we considered a New Keynesian small open-economy model that exhibits an LBD externality in the tradable sector. This type of market failure introduces a trade-off for monetary policy. The LBD externality calls for a policy of exchange rate stabilization which brings tradable production close to the efficient level. On the other hand, in a standard New Keynesian model, higher terms of trade call for an appreciation of the real exchange rate to ensure an efficient allocation of resources across sectors.

Under a calibration consistent with the Canadian data, we find that the trade-off is resolved in favor of allowing a real exchange rate appreciation. This result indicates that stabilizing the nominal exchange rate with monetary policy is a blunt instrument to correct the LBD externality. Any attempt to correct LBD by leaning against an appreciated exchange rate will result in a misallocation of resources and a reduction in welfare. If a government is interested in tackling the problems associated with LBD in a Dutch disease episode, it should use alternative policy instruments. In this model the role of monetary policy should be focused on stabilizing prices subject to nominal rigidities in order to ensure a smooth adjustment toward a situation of higher commodity prices.

One of the arguments in favor of exchange rate intervention is that a real exchange rate appreciation undermines the competitiveness of a country and can have a lasting negative impact on growth and employment creation. The results from a calibrated model indicate that the government can achieve a better outcome by allowing the economy to adjust to higher commodity prices through a real 
exchange rate appreciation. This paper provides theoretical support for the current policy of the Bank of Canada of not intervening in the foreign exchange market. In fact, this central bank has not intervened in the foreign exchange rate market over the last ten years.

There are several interesting extensions for future research. We could evaluate the effectiveness of alternative instruments to correct the LBD externality. One example is to evaluate the impact of a structural balance rule, similar to the one implemented in Chile, in which government spending is insulated from variations in commodity prices. Medina and Soto (2007) follow this approach and evaluate the effects of a structural balance rule in Chile during a boom in copper prices. Another option is to evaluate the implications of increasing competition in goods and labor markets in order to better cope with a Dutch disease episode. Bayoumi, Laxton, and Pesenti (2004) evaluate the impact of these structural policies for the euro area, finding significant effects on GDP and consumption.

We could also explore alternative frictions affecting the tradable sector, which can be operating during a commodity boom. For instance, Caballero and Lorenzoni (2009) evaluate the welfare gains of influencing the real exchange rate when the tradable sector is subject to financial frictions. Finally, it is important to conduct a similar quantitative exercise for a developing small open economy. In a situation in which the monetary authority may lack credibility, stabilizing the exchange rate could be a better alternative to stabilize prices and anchor inflation expectations, as is shown empirically in Rogoff et al. (2004).

\section{Appendix 1. Equilibrium Conditions}

Households

$$
\begin{gathered}
\beta E_{t}\left[\left(1+i_{t}\right) \frac{P_{t}^{C}}{P_{t+1}^{C}}\left(\frac{C_{t}-h C_{t-1}}{C_{t+1}-h C_{t}}\right)\right]=1, \\
\beta E_{t}\left[\left(1+i_{t}^{*}\right) \Theta\left(\mathcal{B}_{t}\right) \frac{P_{t}^{C}}{P_{t+1}^{C}} \frac{\mathcal{E}_{t+1}}{\mathcal{E}_{t}}\left(\frac{C_{t}-h C_{t-1}}{C_{t+1}-h C_{t}}\right)\right]=1, \\
\left(C_{t}-h C_{t-1}\right) \zeta_{L} l_{t}^{\varphi}=\frac{W_{t}}{P_{t}^{C}} .
\end{gathered}
$$


Equations (39) and (40) define the Euler equations for domestic bonds and international bonds, respectively. Labor supply is determined by (41).

Final Goods Producers

$$
\begin{aligned}
P_{t}^{C} F_{Y^{D H}, t} & =P_{t}^{H}, \\
P_{t}^{C} F_{Y^{M}, t} & =P_{t}^{M}, \\
P_{t}^{C} F_{Y^{D N}, t} & =P_{t}^{N},
\end{aligned}
$$

where $Y_{t}^{F}=F\left(Y_{t}^{D H}, Y_{t}^{M}, Y_{t}^{D N}\right)$ is the production function for final goods. Equations (42)-(44) describe the demand for home, imported, and non-tradable inputs, respectively.

\section{Retailers}

The first-order conditions for the retailers in sector $J=H, N$ are

$E_{t}\left[\sum_{i=0}^{\infty}\left(\theta_{J}\right)^{i} \Lambda_{t, t+i}\left(\frac{P_{t}^{J *}(j)}{P_{t+i}^{J}}\right)^{-\epsilon_{J}} Y_{t}^{J}(j)\left[\frac{P_{t}^{J *}(j)}{P_{t+i}^{J}}-\frac{\epsilon_{J}}{\epsilon_{J-1}} \frac{P_{t+i}^{W J}}{P_{t+i}^{J}}\right]\right]=0$,

where $P_{t}^{J}=\left(\theta_{J}\left(P_{t-1}^{J}\right)^{1-\epsilon_{J}}+\left(1-\theta_{J}\right)\left(P_{t}^{J *}\right)^{1-\epsilon_{J}}\right)^{1 /\left(1-\epsilon_{J}\right)}$.

\section{Intermediate Goods Producers}

The first-order conditions for the home and non-tradable goods sectors are

$$
\begin{aligned}
F_{L^{N}, t}^{N} & =\frac{W_{t}}{P_{t}^{W N}}, \\
F_{K^{N}, t}^{N} & =\frac{Z_{t}^{N}}{P_{t}^{W N}}, \\
F_{L^{H}, t}^{H} & =\frac{W_{t}}{P_{t}^{W H}}, \\
F_{K^{H}, t}^{H} & =\frac{Z_{t}^{H}}{P_{t}^{W H}},
\end{aligned}
$$


where $Y_{t}^{N}(n)=F^{N}\left(A_{t}^{N}, L_{t}^{N}(n), K_{t}^{N}(n)\right)$ and $Y_{t}^{H}(h)=$ $F^{H}\left(A_{t}^{H}, H_{t}(h), L_{t}^{H}(h), K_{t}^{H}(h)\right)$ are the production functions for home and non-tradable goods, respectively.

\section{Capital Producers}

For each sector-specific capital producer $J=H, N$, the first-order conditions are

$$
\begin{aligned}
1= & \frac{Q_{t}^{J}}{P_{t}^{C}}\left[S\left(\frac{I_{t}^{J}}{I_{t-1}^{J}}\right)+S^{\prime}\left(\frac{I_{t}^{J}}{I_{t-1}^{J}}\right) \frac{I_{t}^{J}}{I_{t-1}^{J}}\right] \\
& -E_{t}\left[\Lambda_{t, t+1} \frac{Q_{t+1}^{J}}{P_{t+1}^{C}}\left[S^{\prime}\left(\frac{I_{t+1}^{J}}{I_{t}^{J}}\right)\left(\frac{I_{t+1}^{J}}{I_{t}^{J}}\right)^{2}\right]\right], \\
\frac{Q_{t}^{J}}{P_{t}^{C}}= & E_{t}\left[\Lambda_{t, t+1}\left[\frac{Z_{t}^{J}}{P_{t}^{C}}+\frac{Q_{t+1}^{J}}{P_{t+1}^{C}}(1-\delta)\right]\right] .
\end{aligned}
$$

Equations (50) and (51) determine the evolution of investment $I_{t}^{J}$ and the real price of capital $\frac{Q_{t}^{J}}{P_{t}^{C}}$ in each sector.

Monetary Policy Rule

Monetary policy is characterized by a Taylor-type rule:

$$
\left(\frac{1+i_{t}}{1+i}\right)=\left(\frac{1+i_{t-1}}{1+i}\right)^{\psi_{i}}\left(\frac{Y_{t}}{\bar{Y}_{t}}\right)^{\left(1-\psi_{i}\right) \psi_{y}}\left(\frac{\pi_{C, t}}{\bar{\pi}}\right)^{\left(1-\psi_{i}\right) \psi_{\pi}}\left(\frac{s_{t}}{\bar{s}}\right)^{\left(1-\psi_{i}\right) \psi_{s}},
$$

where $i_{t}, Y_{t}, \pi_{C, t}$, and $s_{t}$ are the nominal interest rate, GDP, CPI inflation, and the depreciation rate, respectively.

Market Clearing Conditions

$$
\begin{gathered}
L_{t}=\left(\int_{0}^{1} L_{t}^{N}(n) d n\right)+\left(\int_{0}^{1} L_{t}^{H}(h) d h\right), \\
K_{t}^{J}=\left(\int_{0}^{1} K_{t}^{J}(j) d j\right), J=H, N, \\
Y_{t}^{D N}=Y_{t}^{N},
\end{gathered}
$$




$$
\begin{gathered}
Y_{t}^{D H}+C_{t}^{H *}=Y_{t}^{H} \\
Y_{t}^{F}=C_{t}+I_{t}^{H}+I_{t}^{N} \\
\mathcal{E}_{t} B_{t}^{*}=\left(1+i_{t-1}^{*}\right) \Theta\left(\mathcal{B}_{t-1}\right) \mathcal{E}_{t} B_{t-1}^{*}+P_{t}^{M} Y_{t}^{M}-P_{t}^{H} C_{t}^{H *}-P_{t}^{x} X_{t} .
\end{gathered}
$$

Equations (53) and (54) are the market clearing conditions in the labor and capital markets. Equations (55)-(57) define the market clearing conditions for the non-tradable, home, and final goods, respectively. (58) describes the law of motion for international bonds, where $C_{t}^{H *}=\gamma^{*}\left(\frac{P_{H, t}}{\mathcal{E}_{t} P_{t}^{M *}}\right)^{-\eta^{*}} C_{t}^{*}$ is the foreign demand for home goods.

\section{Appendix 2. Internalization of Learning-by-Doing}

When the LBD mechanism is internalized, the problem of firms in the home goods sector is the following:

$$
\begin{aligned}
\Pi_{t}= & \max _{H_{t+i}, L_{t+i}^{H}, K_{t+i}^{H}} \\
& \times E_{t}\left\{\sum_{i=0}^{\infty} \Lambda_{t, t+i} \frac{P_{t+i}^{W H} Y_{t+i}^{H}(h)-W_{t+i} L_{t+i}^{H}(h)-Z_{t+i}^{H} K_{t+i}^{H}(h)}{P_{t+i}^{C}}\right\}
\end{aligned}
$$

subject to the law of motion of organizational capital:

$$
H_{t+1}(h)=\left[H_{t}(h)\right]^{\phi_{H}}\left[Y_{t}^{H}(h)\right]^{\mu_{H}},
$$

where $\Lambda_{t, t+i}$ is the stochastic discount factor. The first-order conditions of the firm are given by

$$
\begin{gathered}
\frac{W_{t}}{P_{t}^{C}}=\frac{P_{t}^{W H}}{P_{t}^{C}} F_{L^{H}, t}^{H}+\frac{Q_{t}^{O}}{P_{t}^{C}} G_{L^{H}, t}, \\
\frac{Z_{t}^{H}}{P_{t}^{C}}=\frac{P_{t}^{W H}}{P_{t}^{C}} F_{K^{H}, t}^{H}+\frac{Q_{t}^{O}}{P_{t}^{C}} G_{K^{H}, t}, \\
\frac{Q_{t}^{O}}{P_{t}^{C}}=E_{t}\left[\Lambda_{t, t+1}\left[\frac{P_{t+1}^{W H}}{P_{t+1}^{C}} F_{H, t+1}^{H}+\frac{Q_{t+1}^{O}}{P_{t+1}^{C}} G_{K^{H}, t+1}\right]\right],
\end{gathered}
$$

where $Y_{t}^{H}(h)=F^{H}\left(A_{t}^{H}, H_{t}(h), L_{t}^{H}(h), K_{t}^{H}(h)\right)$ is the production function of home goods, $H_{t+1}(h)=G\left(A_{t}^{H}, H_{t}(h), L_{t}^{H}(h), K_{t}^{H}(h)\right)$ is 
the law of motion for organizational capital, and $\frac{Q_{t}^{O}}{P_{t}^{C}}$ is the real price of organizational capital. When we consider a model with internalization of LBD, the first-order conditions (48)-(49) are replaced by (60)-(62). It is possible to rewrite the internalization component of (60) $\left(\frac{Q_{t}^{O}}{P_{t}^{C}} G_{L^{H}, t}\right)$ in terms of a subsidy to the production of home goods. The subsidy can be defined as

$$
\left(1+\tau_{t}^{H}\right) \frac{P_{t}^{W H}}{P_{t}^{C}} F_{L^{H}, t}^{H}=\frac{W_{t}}{P_{t}^{C}}=\frac{P_{t}^{W H}}{P_{t}^{C}} F_{L^{H}, t}^{H}+\frac{Q_{t}^{O}}{P_{t}^{C}} G_{L^{H}, t},
$$

where $\tau_{t}^{H}$ is a state-contingent subsidy that eliminates the wedge between the socially optimal outcome and the allocation under the LBD externality.

\section{References}

Adolfson, M., S. Laséen, J. Lindé, and M. Villani. 2007. "Bayesian Estimation of an Open Economy DSGE Model with Incomplete Pass-Through." Journal of International Economics 72 (2): 481511.

Aguiar, M., and G. Gopinath. 2007. "Emerging Market Business

Cycles: The Cycle is the Trend." Journal of Political Economy 115 (1): 69-102.

Bayoumi, T., D. Laxton, and P. Pesenti. 2004. "Benefits and Spillovers of Greater Competition in Europe: A Macroeconomic Assessment." NBER Working Paper No. 10416.

Benigno, P. 2004. "Optimal Monetary Policy in a Currency Area." Journal of International Economics 63 (2): 293-320.

Bils, M., and P. Klenow. 2004. "Some Evidence on the Importance of Sticky Prices." Journal of Political Economy 112 (5): 947-85.

Blanchard, O., and C. Kahn. 1980. "The Solution of Linear Difference Models under Rational Expectations." Econometrica 48 (5): 1305-11.

Caballero, R., and G. Lorenzoni. 2009. "Persistent Appreciations and Overshooting: A Normative Analysis." MIT Working Paper.

Calvo, G. 1983. "Staggered Prices in a Utility-Maximizing Framework." Journal of Monetary Economics 12 (3): 383-98.

Calvo, G., and C. Reinhart. 2002. "Fear of Floating." Quarterly Journal of Economics 117 (2): 379-408. 
Chang, Y., J. F. Gomes, and F. Schorfheide. 2002. "Learningby-Doing as a Propagation Mechanism." American Economic Review 92 (5): 1498-1520.

Chen, Y., and K. Rogoff. 2003. "Commodity Currencies." Journal of International Economics 60 (1): 133-60.

Christiano, L. J., M. Eichenbaum, and C. L. Evans. 2005. "Nominal Rigidities and the Dynamic Effects of a Shock to Monetary Policy." Journal of Political Economy 113 (1): 1-45.

Clarke, A. 2008. "Learning-by-Doing and Productivity Dynamics in Manufacturing Industries." Research Paper No. 1032, University of Melbourne.

Cooper, R., and A. Johri. 2002. "Learning-by-Doing and Aggregate Fluctuations." Journal of Monetary Economics 49 (8): 1539-66.

Correia, I., J. P. Nicolini, and P. Teles. 2008. "Optimal Fiscal and Monetary Policy: Equivalence Results." Journal of Political Economy 116 (1): 141-70.

de Resende, C., A. Dib, and M. Kichian. 2010. "Alternative Optimized Monetary Policy Rules in Multi-Sector Small Open Economies: The Role of Real Rigidities." Bank of Canada Working Paper No. 2010-9.

Devereux, M., and C. Engel. 2003. "Monetary Policy in the Open Economy Revisited: Price Setting and Exchange-Rate Flexibility." Review of Economic Studies 70 (4): 765-83.

Friedman, M. 1953. "The Case for Flexible Exchange Rates." In Essays in Positive Economics, 157-203. Chicago: University of Chicago Press.

Goodfriend, M., and R. King. 2001. "The Case for Price Stability." NBER Working Paper No. 8423.

Greenwood, J., Z. Hercowitz, and G. Huffman. 1988. "Investment, Capacity Utilization, and the Real Business Cycle." American Economic Review 78 (3): 402-17.

Ireland, P. 1996. "The Role of Countercyclical Monetary Policy." Journal of Political Economy 104 (4): 704-23.

Justiniano, A., and B. Preston. 2008. "Can Structural Small Open Economy Models Account for the Influence of Foreign Disturbances?" NBER Working Paper No. 14547.

Krugman, P. 1987. "The Narrow Moving Band, the Dutch Disease, and the Competitive Consequences of Mrs. Thatcher." Journal of Development Economics 27 (1-2): 41-55. 
Lama, R., and J. Medina. 2011. "Optimal Monetary Policy and Social Insurance." The B.E. Journal of Macroeconomics 11 (1): Contributions, Article 10.

Lev, B., and S. Radhakrishnan. 2003. "The Measurement of FirmSpecific Organizational Capital." NBER Working Paper No. 9581.

Lubik, T. A., and F. Schorfheide. 2007. "Do Central Banks Respond to Exchange Rate Movements? A Structural Investigation." Journal of Monetary Economics 54 (4): 1069-87.

Lucas, R. 1987. Models of Business Cycles. New York: Basil Blackwell.

Medina, J., and C. Soto. 2007. "Copper Price, Fiscal Policy, and Business Cycle in Chile." Central Bank of Chile Working Paper No. 458.

Murchison, S., and A. Rennison. 2006. "ToTEM: The Bank of Canada's New Quarterly Projection Model." Bank of Canada Technical Report No. 97.

Nakamura, E., and J. Steinsson. 2008. "Five Facts about Prices: A Reevaluation of Menu Cost Models." Quarterly Journal of Economics 123 (4): 1415-64.

Neumeyer, P., and F. Perri. 2005. "Business Cycles in Emerging Economies: The Role of Interest Rates." Journal of Monetary Economics 52 (2): 345-80.

Rabanal, P., and V. Tuesta. 2010. "Euro-Dollar Real Exchange Rate Dynamics in an Estimated Two-Country Model: An Assessment." Journal of Economic Dynamics and Control 34 (4): 78097.

Rogoff, K., A. M. Husain, A. Mody, R. Brooks, and N. Oomes. 2004. "Evolution and Performance of Exchange Rate Regimes." IMF Occasional Paper No. 229.

Rotemberg, J. 1982. "Monopolistic Price Adjustment and Aggregate Output." Review of Economic Studies 49 (4): 517-31.

Schmitt-Grohé, S. 1998. "The International Transmission of Economic Fluctuations: Effects of U.S. Business Cycles on the Canadian Economy." Journal of International Economics 44 (2): 25787.

Schmitt-Grohé, S., and M. Uribe. 2001. "Stabilization Policy and the Costs of Dollarization." Journal of Money, Credit, and Banking 33 (2): 482-509. 
. 2003. "Closing Small Open Economy Models." Journal of International Economics 61 (1): 163-85.

2004a. "Optimal Fiscal and Monetary Policy Under Sticky Prices." Journal of Economic Theory 114 (2): 198-230.

- 2004b. "Solving Dynamic General Equilibrium Models Using a Second-Order Approximation to the Policy Function." Journal of Economic Dynamics and Control 28 (4): 755-75.

- 2005. "Optimal Fiscal and Monetary Policy in a MediumScale Macroeconomic Model: Expanded Version." NBER Working Paper No. 11417.

- 2007. "Optimal Simple and Implementable Monetary and Fiscal Rules." Journal of Monetary Economics 54 (6): 1702-25. Smets, F., and R. Wouters. 2007. "Shocks and Frictions in the US Business Cycles: A Bayesian DSGE Approach." American Economic Review 97 (3): 586-606.

Taylor, J. 1999. "Staggered Price and Wage Setting in Macroeconomics." In Handbook of Macroeconomics, Vol. 1B, ed. J. B. Taylor and M. Woodford, 1341-97 (chapter 15). North-Holland. Van Wijnbergen, S. 1984. "The 'Dutch Disease': A Disease After All?" Economic Journal 94 (373): 41-55. 